\title{
Modeling Mechanical Properties Of Knitted Fabric Composites - Part I: Overview And Geometric Description
}

\author{
Zheng-Ming Huang \\ Department of Engineering Mechanics, Tongii University, \\ 1239 Siping Road, Shanghai 200092, P. R. China. \\ E-mail: huningmramail.tongii.edu.cn \\ S. Ramakrishna \\ Biomaterials Laboratory, Division of Bioengineering, \\ Department of Mechanical Engineering \\ National University of Singapore, 10 Kent Ridge Crescent, \\ Singapore 119260
}

\begin{abstract}
Knitted fabric composites are being considered as attractive candidates for a number of engineering applications. An essential issue involved is to model and characterize their mechanical properties especially their load carrying capacity. In this regard, a systematic research program has been recently carried out by the present authors and their co-workers, making use of an efficient micromechanics theory, i.e., the Bridging Model. The composites studied were made from epoxy and elastomer matrices reinforced with plain, interlock, and Milano rib knit structures. Both single layer and multiplayer knitted fabric composites with different fabric lay-ups have been investigated. The composite properties under study include stiffness, strength, and whole rubber-elastic stress-strain curve. These investigations are reviewed and summarized in this series of papers. The present paper focuses on the overview and geometric description. Reports of detailed simulation procedures, experimental evidences, correlation between theoretical results and experiments, and parametric studies for various kinds of knitted fabric composites will be given in the subsequent papers.
\end{abstract}

Key words: Knitted fabric composite, polymer composite, mechanical property, modeling, geometric description

\section{INTRODUCTION}

Knitted fabrics are produced using interlocking of loops of yarns or fiber bundles. Traditionally, these fabrics are employed in the clothing and apparel industry. Nowadays, with the availability of high performance and superior quality fibers such as carbon/graphite, glass, and aramid, and also versatile three-dimensional fiber preforming machines, knitted fabrics are also finding another important application in the composite industry. Composites with knitted fabric reinforcement have received increasing attention in recent years. Compared with unidirectional (UD) fiber reinforced composites and with some other types of textile fabric such as woven and braided fabric reinforced composites, knitted fabric composites usually have interior mechanical properties. Figures 1 and 2 show stiffnesses and tensile strengths of five common fibrous composites in their respective main direction, made using same/similar glass fiber and epoxy matrix. Figures 3 and 4 show normalized (with respect to the 


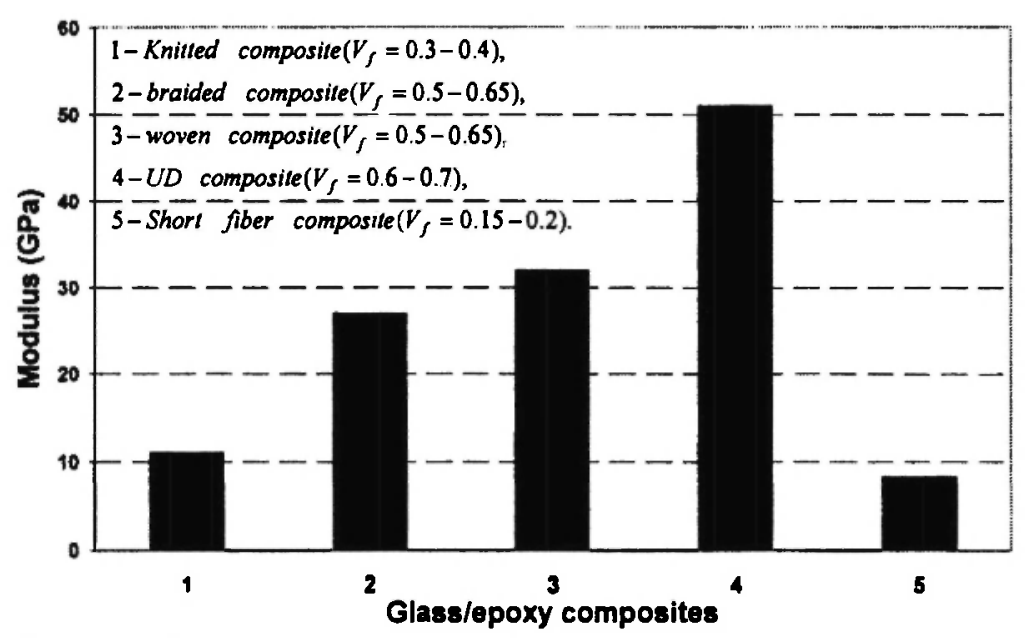

Fig. 1: Main moduli of different fibrous composites made using the same/ similar constituent glass fiber and epoxy matrix materials.

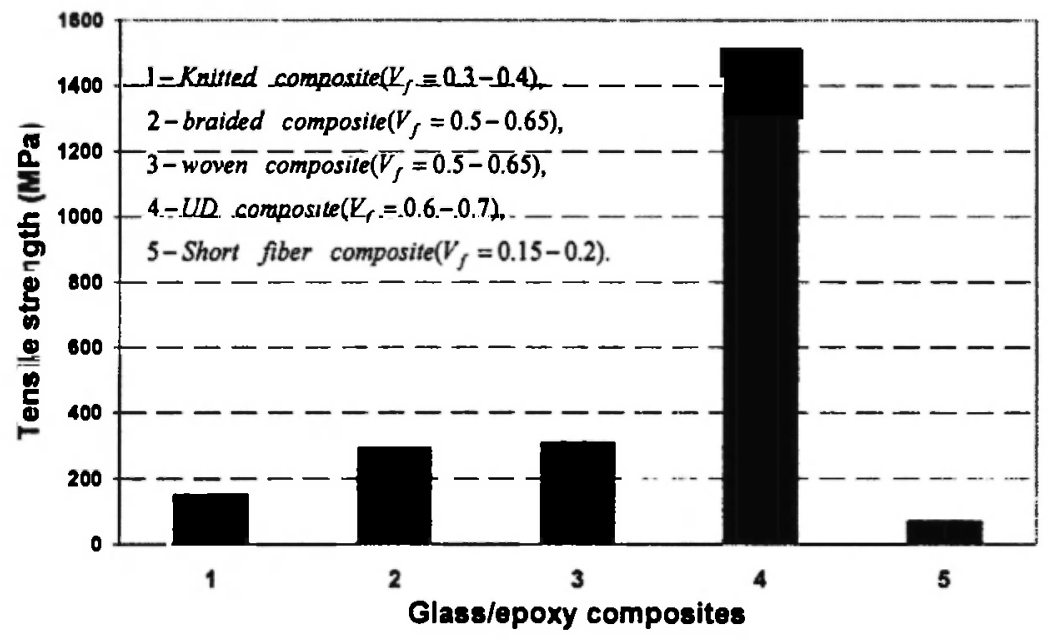

Fig. 2: Main tensile strengths of different fibrous composites made using the same/similar constituent glass fiber and epoxy matrix materials.

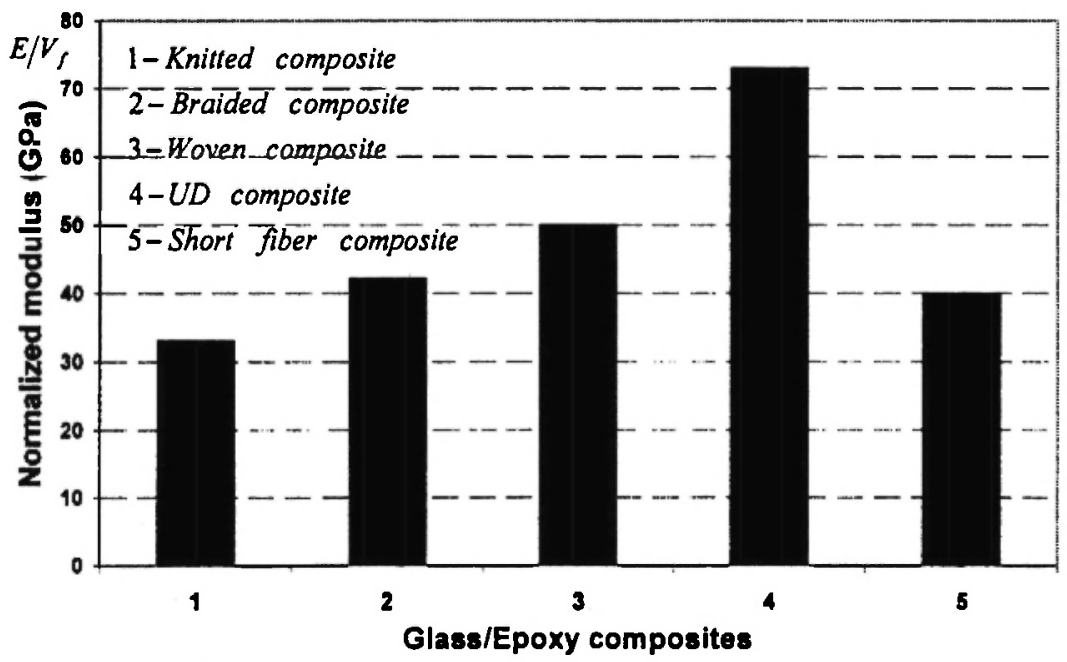

Fig. 3: Normalized (with respect to the fiber volume fraction) modulus of different fibrous composites in their main directions. 


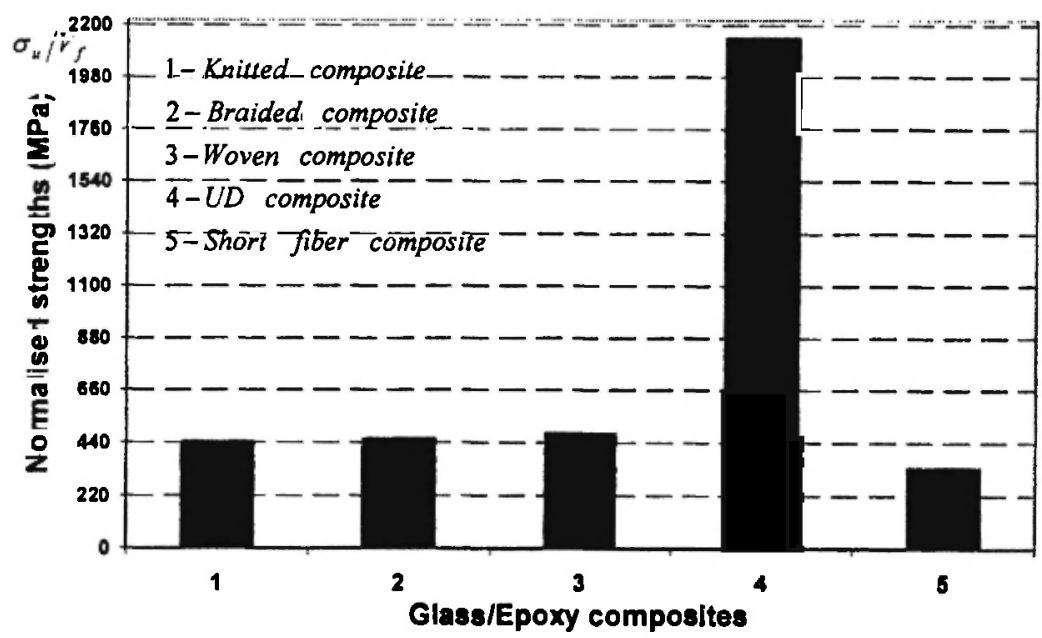

Fig. 4: Normalized (with respect to the fiber volume fraction) strength of different fibrous composites in their main directions.

fiber volume fraction) results of the stiffnesses and strengths, which were obtained by dividing the corresponding quantities in Figs. 1 and 2 by the respective volume fractions, $V_{f}$. From the figures, it is seen that the actual stiffness and strength of composites reinforced with common knitted fabrics (type I fabrics, see Fig. 21) are only relatively higher than those of short fiber reinforced composites, whereas the normalized values of all the fibrous composites except for the UD composite are comparable with each other. Although knitted fabric composites generally have low stiffness and strength due to their low fiber volume fraction, they do have several advantages over the other fibrous composites, including mass productivity, low fabrication cost, superior resistance to impact, and high ability to conform to complicated contours $/ 1-5 /$. In addition, by inserting straight yarns in the knitted fabrics, the resulting composites can achieve relatively high stiffness and strength comparable with those of woven fabric composites, as indicated in Fig. 5. The fiber volume fractions of knitted fabric composites can also be increased to as high as more than $50 \%$ through some techniques $/ 1 /$, and hence the mechanical properties of the composites elevate. Furthermore, an almost infinite variety of knitted flat and net-shape/nearnet-shape fabrics can be produced using the existing knitting machines $/ 1,6 /$. Reinforcing these fabrics in different polymer matrices such as thermoset,

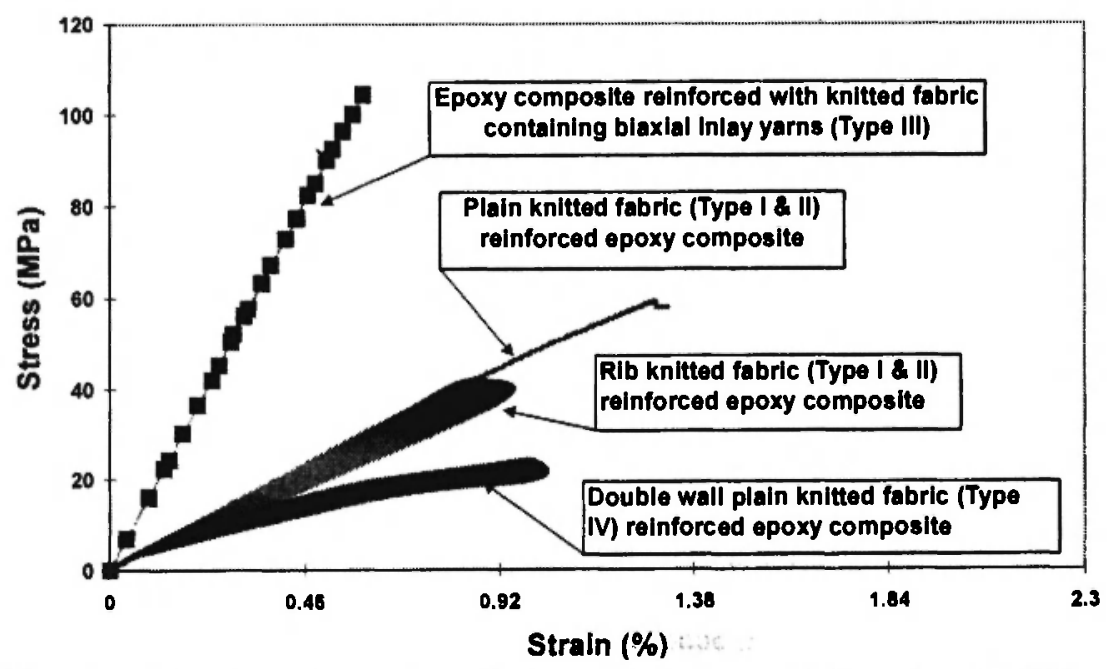

Fig. 5: Typical in-plane stress/strain performances of epoxy /composites reinforced with different knitted glass fiber fabric forms (see Fig. 21) loaded in wale direction. 
thermoplastic, and elastomer materials can make composites with various mechanical performances $/ 7 /$. The tensile stress-strain responses of three typical such composites are plotted in Fig. 6 through Fig. 8. The tensile stress-strain curve of a composite, made using knitted glass fiber fabric and thermoset epoxy matrix, is grossly linear with a small ultimate failure strain, $1.3 \%$, shown in Fig. 6. In the case of knitted glass fiber fabric reinforced thermoplastic polypropylene composite material, the stress-strain curve changes from an initial linear elastic relationship to significantly non-linear elasto-plastic relationship with an intermediate ultimate failure strain of $8.5 \%$, as indicated in Fig. 7. It is seen that the matrix polymers used in these two composites mainly cause the difference in stress-strain responses. A highly flexible stress-strain behavior could be achieved by reinforcing a knitted fabric in an elastomeric material. The typical stress-strain curve of a knitted polyester fiber fabric reinforced polyurethane elastomer is graphed in Fig. 8. The stress-strain behavior is characterized by a small initial linear elastic relationship, followed by non-linear behavior with large ultimate failure strain of $86.3 \%$. In other words, by selecting the type of matrix materials, the mechanical characteristics of a knitted fabric composite can be tailored from rigid to flexible.

On the other hand, the mechanical performance of knitted fabric composites can also vary to a certain

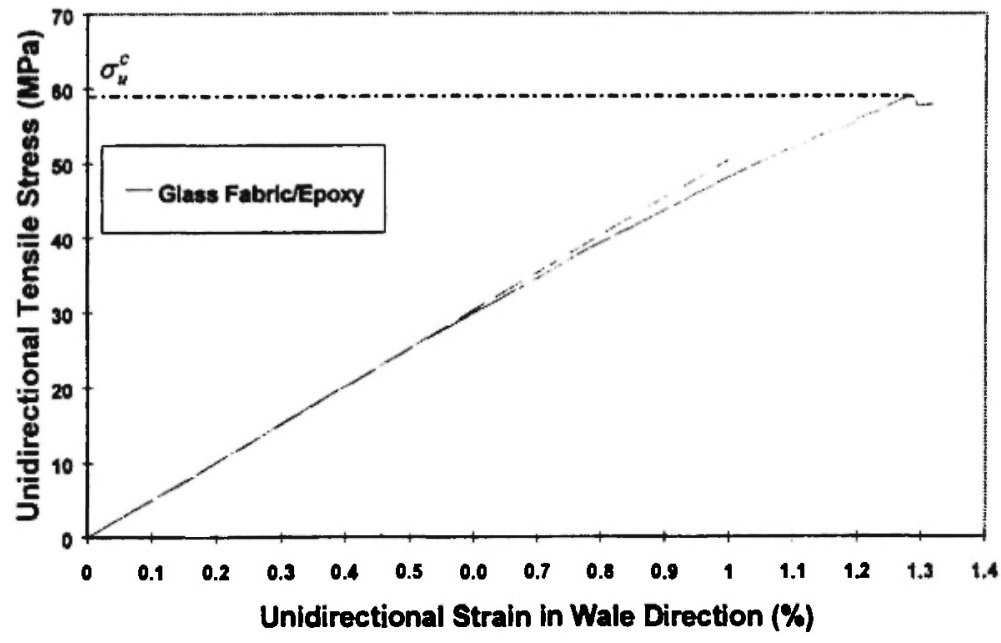

Fig. 6: Tensile stress-strain curve of a plain weft knitted glass fiber fabric reinforced thermoset epoxy matrix composite.

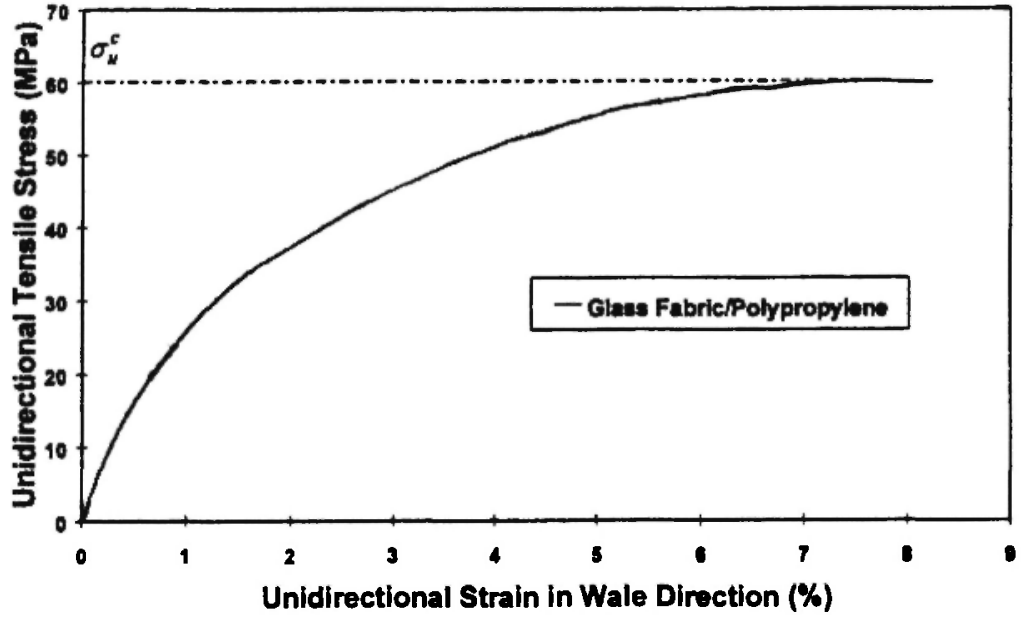

Fig. 7: Tensile stress-strain curve of a plain weft knitted glass fiber fabric reinforced thermoplastic polypropylene matrix composite. 


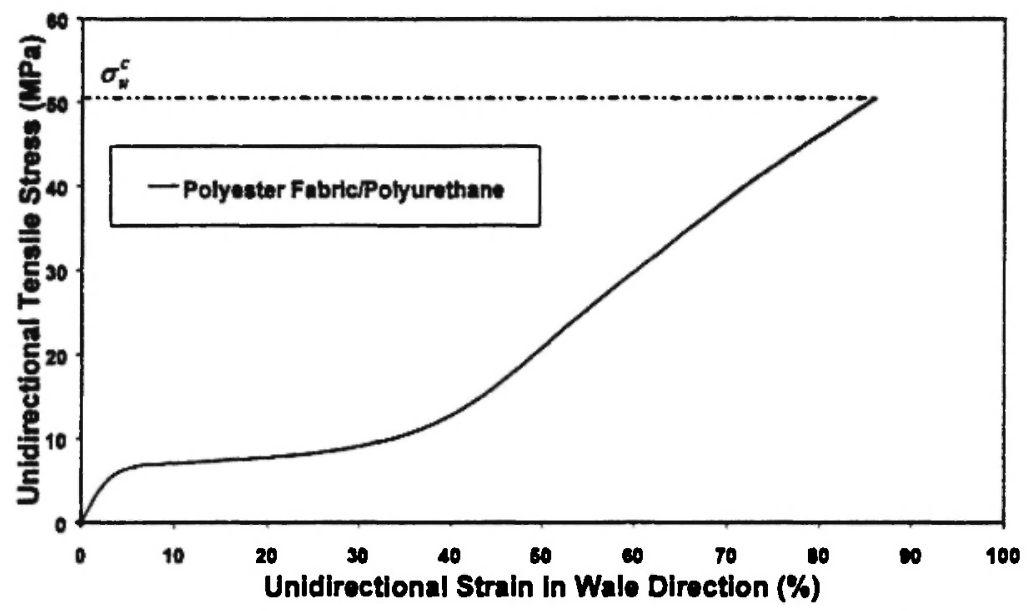

Fig. 8: Tensile stress-strain curve of an interlock weft knitted polyester fiber fabric reinforced elastomer polyurethane matrix composite.

extent by changing fiber materials and fabric reinforcement pattern. Fig. 9 plots the uniaxial tensile stress-strain curves of the same epoxy based composites reinforced with knitted fabrics made from three typical engineering fibers, i.e. carbon, glass, and kevlar. It is seen that the knitted carbon fabric composite generally gives the highest stiffness and strength. Whereas the stiffnesses of the glass and kevlar 49 fabric composites are comparable, they do have different ultimate strengths. The composite reinforced by the kevlar fabric has a higher tensile strength. Using the same fiber yarn and matrix materials, different fabric patterns result in different mechanical performance of the composites, as shown in Fig. 5. When biaxial inlay yarns are inserted into a plain weft knitted fabric, the resulting composite exhibits the highest stiffness and strength behaviors. This is because the inlay yarns have sustained most of the load, resembling a woven fabric composite. Both the rib and the plain knitted fabric composites have comparable stiffness. However, the plain knitted fabricreinforced composite usually gives higher tensile strength if loaded in the fabric wale direction. On the other hand, composites reinforced with double-wall fabrics, although exhibiting better properties in the thickness direction, give the least stiffness and strength in the wale direction of the fabric plane. Figs 10 and 11

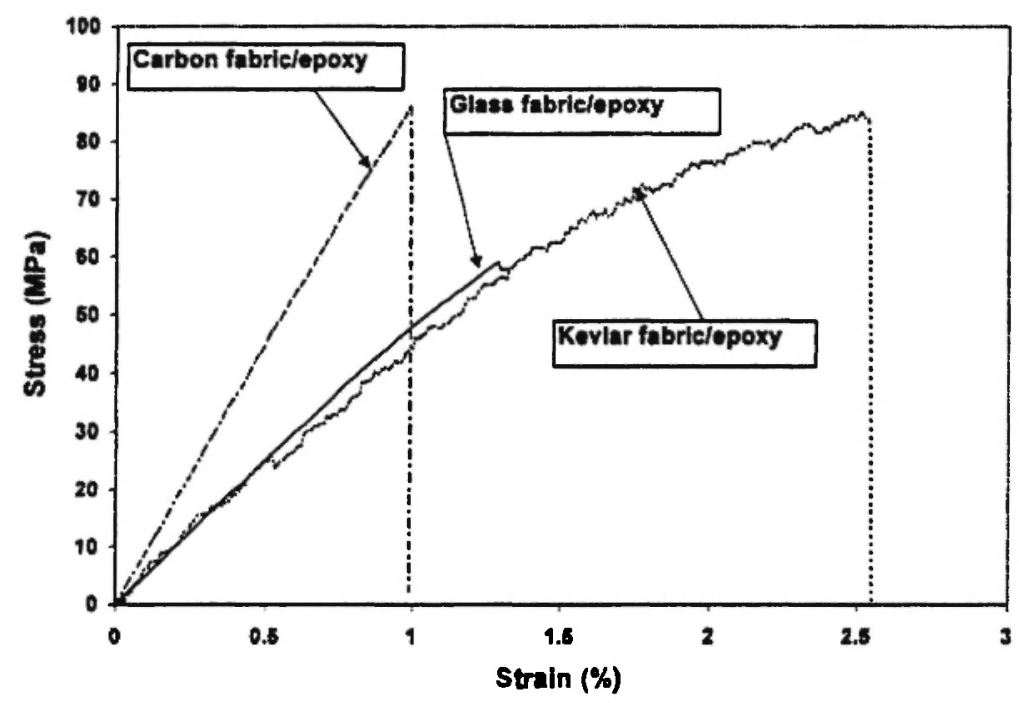

Fig. 9: Typical uniaxial tensile stress/strain curves of plain weft knitted fabric reinforced epoxy matrix composites with different fiber materials. 


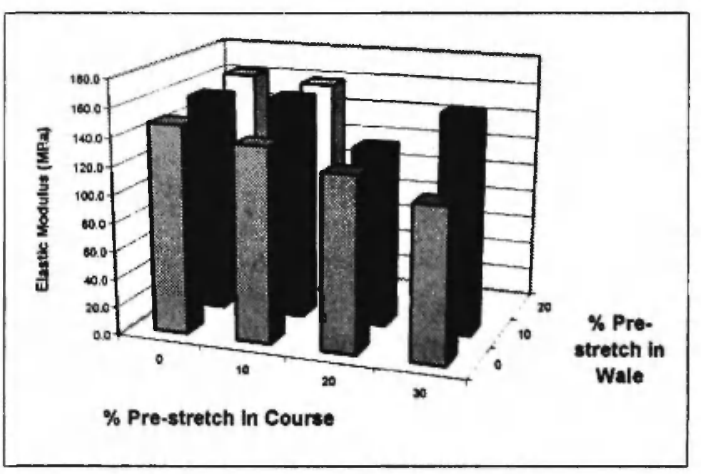

(a)

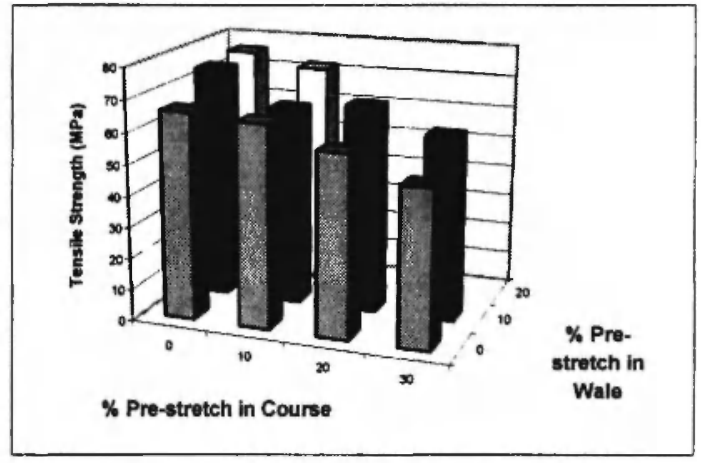

(b)

Fig. 10: Measured (a) elastic modulus, (b) tensile strength of an elastomeric fabric composite in wale direction versus degree of biaxial pre-stretching.

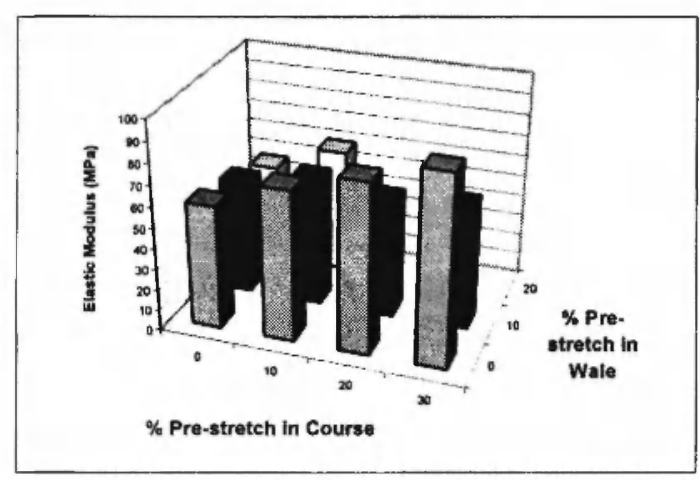

(a)

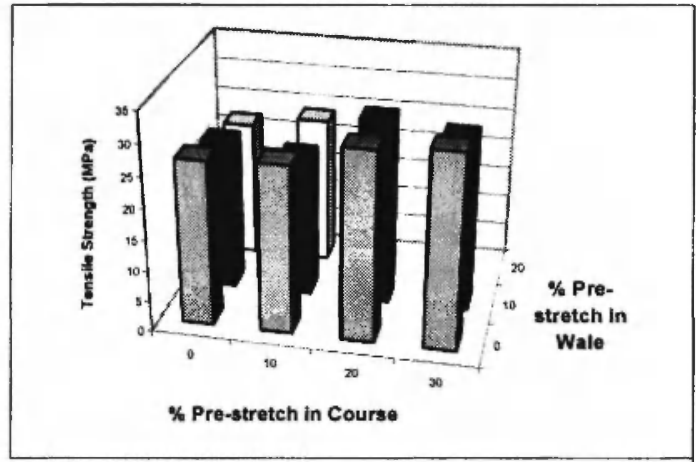

(b)

Fig. 11: Measured (a) elastic modulus, (b) tensile strength of an elastomeric fabric composite in course direction verşus degree of biaxial pre-stretching.

indicate the variations of elastic modulus and tensile strength of an interlock knitted fabric reinforced elastomer composite varied with amount of pre-stretch for the fabric in two different directions /8/. From these figures, one can see that when the composite was tested in the same direction as pre-stretching, providing that the pre-stretching in the other direction remained the same, the modulus and strength generally increased with increasing percentage of pre-stretching. When tested in the direction normal to the pre-stretching the opposite effect was seen. More experimental evidences regarding the fabric pre-stretching effect on the composite properties can be found in Ref. /8/. Furthermore, the mechanical properties of a knitted fabric composite are different in different directions $/ 9 /$. The tensile modulus and strength of knitted kevlar fiber fabric reinforced epoxy composites versus off-axis angle are graphed in
Figs. 12 and 13. In the figures, the $0^{\circ}$-direction refers to the fabric wale direction, whereas the $90^{\circ}$-direction refers to the fabric course direction. Both the figures show that the tensile behaviors of the knitted fabric composite decrease gradually from the wale direction to the course direction, similarly to those of a unidirectional composite with varying an off-axis angle from $0^{0}$-direction (fiber axial or longitudinal direction) to $90^{\circ}$-direction (transverse direction) $/ 10,11 \%$. However, the unidirectional composites have much more dramatic variation in off-axial tensile behavior. The corresponding off-axial tensile fracture modes of the knitted fabric composites are indicated in Figs. 14 and 15. The figures indicate that the tensile fracture of $0^{\circ}$ and $90^{\circ}$ specimens happened in the direction perpendicular to the loading direction. In the other offaxis $\left(30^{\circ}, 45^{\circ}\right.$, and $\left.60^{\circ}\right)$ cases, the fracture occurred at 


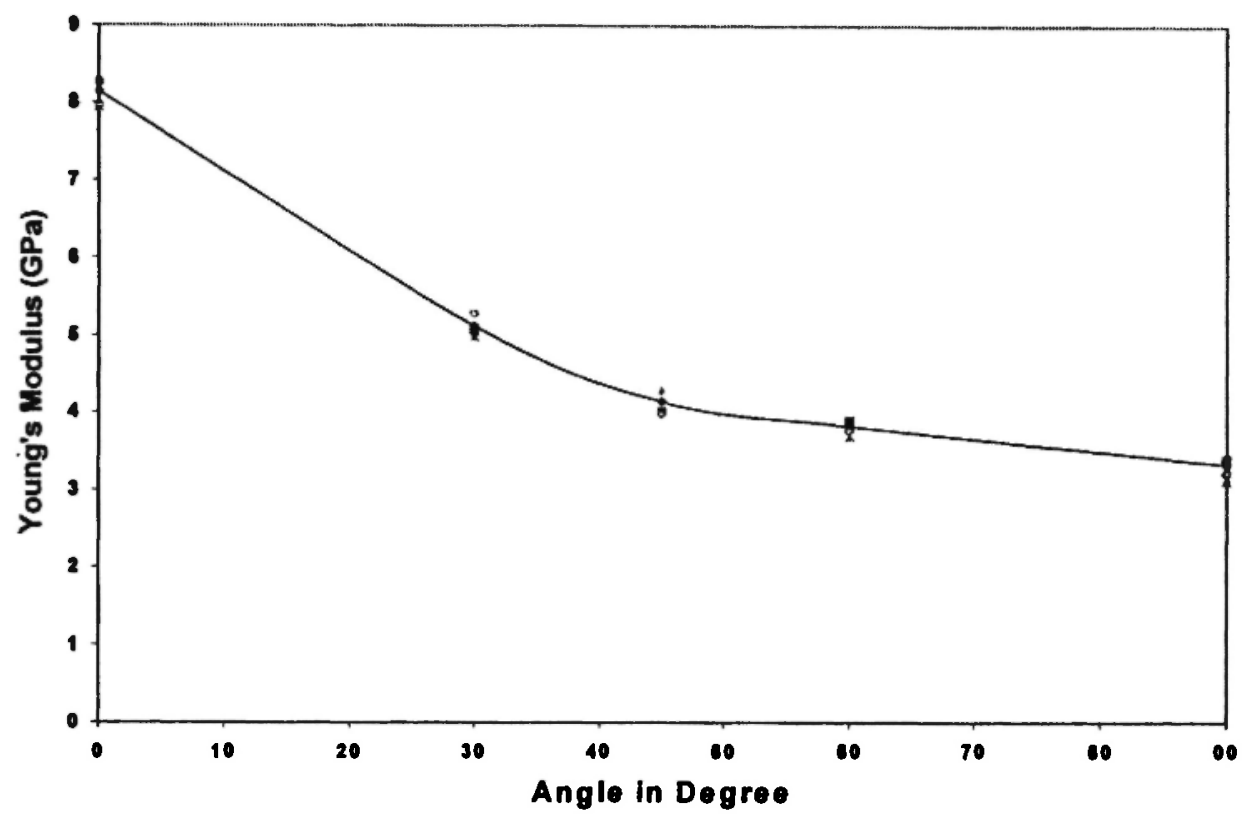

Fig. 12: Tensile modulus of single-layer knitted fabric reinforced composite varied with off-axial angle, where $0^{\circ}$ direction refers to the fabric wale direction.

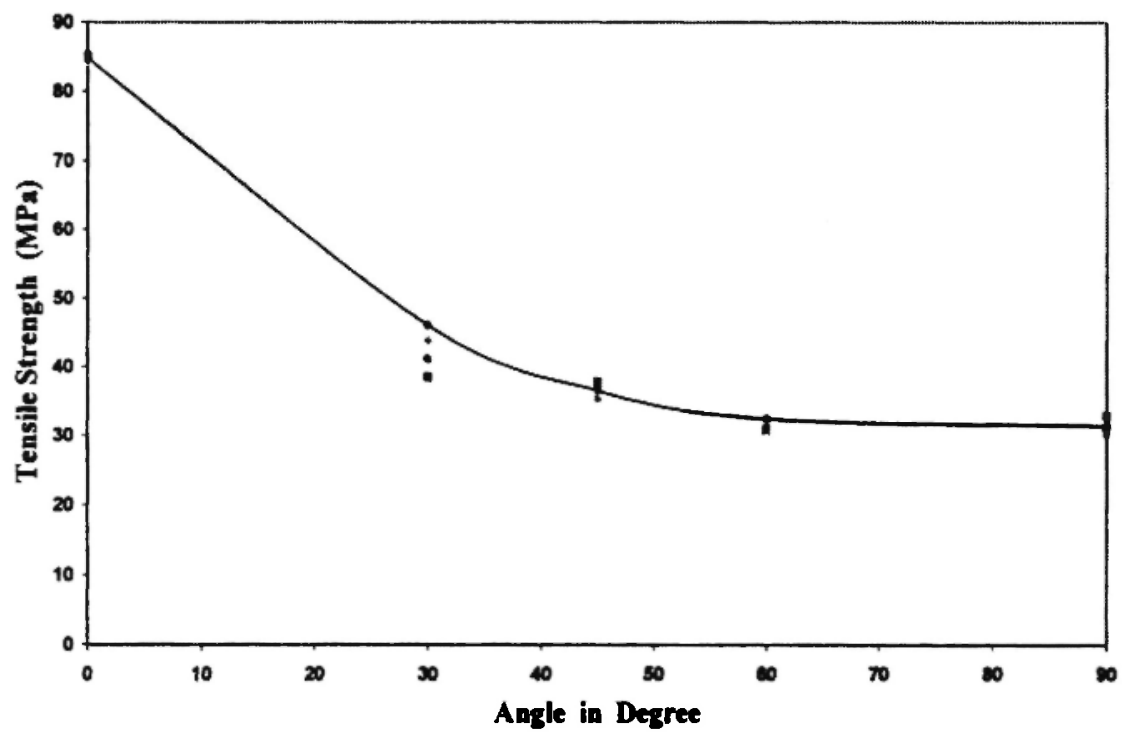

Fig. 13: Tensile strength of single-layer knitted fabric reinforced composite varied with off-axial angle, where $0^{0}$ direction refers to the fabric wale direction.

the respective angles to the axis of the specimens. It seems that except for the $0^{\circ}$ (wale) directional specimen, all the other off-axial specimens fractured due to a tensile stress component perpendicular to the wale direction.
These experimental evidences clearly indicate that the mechanical properties of knitted fabric composites are essentially anisotropic. Changing the constituent materials and the fabric reinforcement pattern/geometry, the mechanical performance of a knitted fabric 


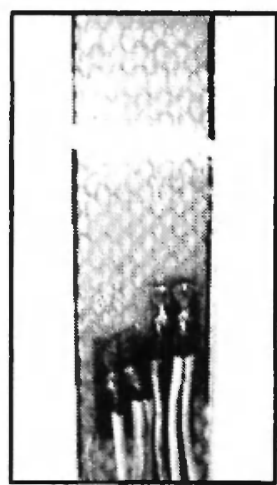

(a) $0^{0}$ specimen

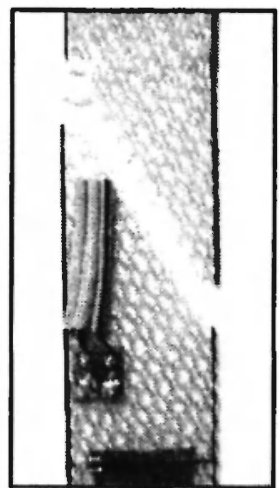

(b) $30^{\circ}$ specimen

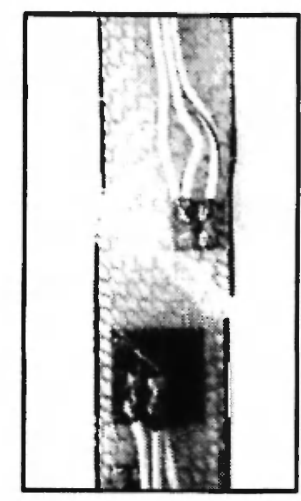

(c) $45^{0}$ specimen

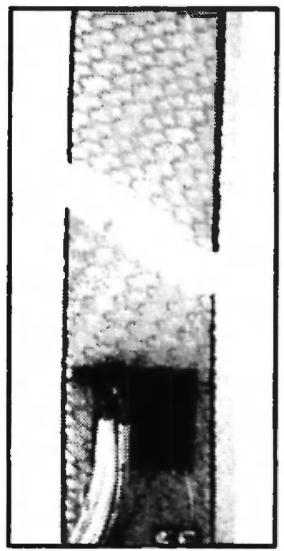

(d) $60^{\circ}$ specimen

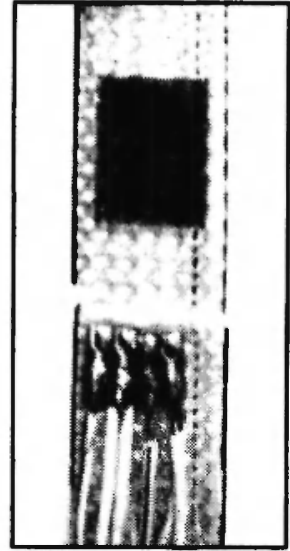

(e) $90^{\circ}$ specimen

Fig. 14: Tensile fractures of a plain weft knitted Kevlar fiber fabric reinforced epoxy matrix composite cut in different off-axial directions subjected to a uniaxial load.

composite can be achieved differently. An overview of various variables that can influence the mechanical properties of knitted fabric composites is shown in Fig. 16 , in which the warp knitted and weft knitted fabrics can be further sub-classified, such as into those in Figs. 17 and 18 (Ref. /12/). From Fig. 16, one can see that the mechanical performance of a knitted fabric composite is complicated by many parameters. In order to make use of knitted fabric reinforced composites most efficiently and further to design optimal composites, their mechanical properties, including the quantitative influences of the various parameters, must be thoroughly understood. As shown above, these properties include elastic modulus, elasto-plastic response, ultimate strength, nonlinear and rubber-like stress-strain curve, etc.

The conventional approach to characterize material properties follows a pragmatic philosophy that demands an experimental determination of the material response characteristics. While this approach offers the best advantage for isotropic materials because only one single uniaxial loading test is generally sufficient, it does have limitations for anisotropic composite materials. The introduction of the directional dependence of the mechanical properties of anisotropic composite materials along with the variation of these 


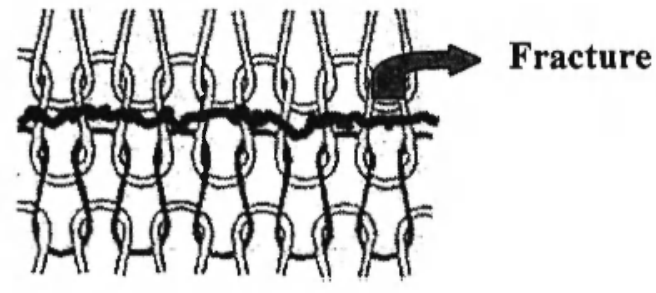

(a) $0^{0}$ specimen

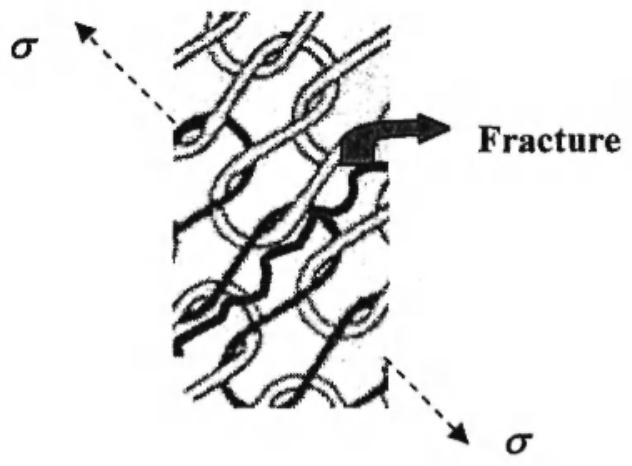

(c) $45^{\circ}$ specimen

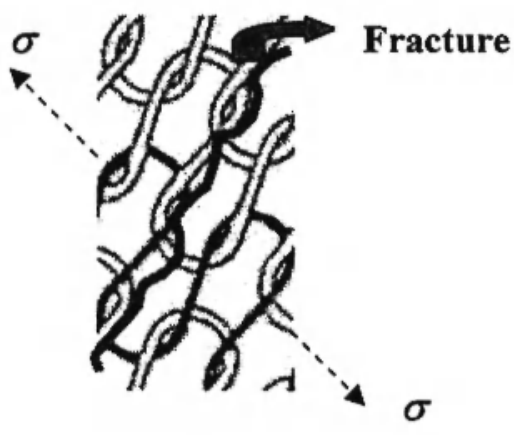

(b) $30^{\circ}$ specimen

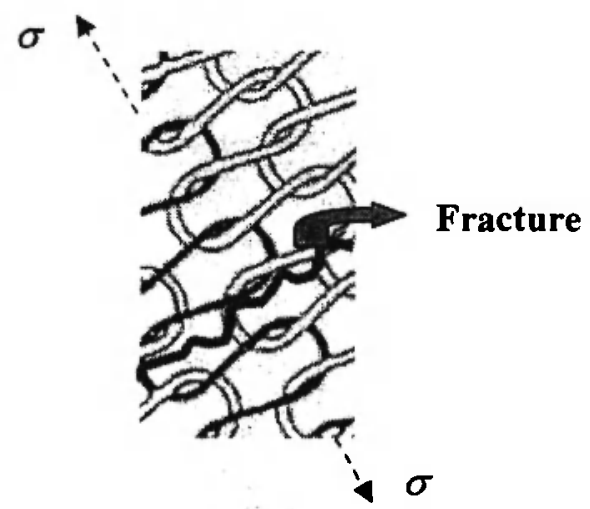

(d) $60^{\circ}$ specimen

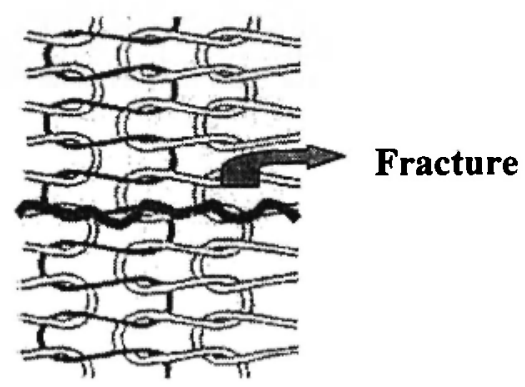

(e) $90^{\circ}$ specimen

Fig. 15: Schematic diagrams of fracture modes of knitted fabric specimens cut in different off-axial angles subjected to a uniaxial load.

properties with composition, orientation, and packing geometry of the components greatly magnifies the labour and expense involved in the experimental determination of the overall material response characteristics. The problem becomes more serious in knitted fabric composites. As the thickness of such a 


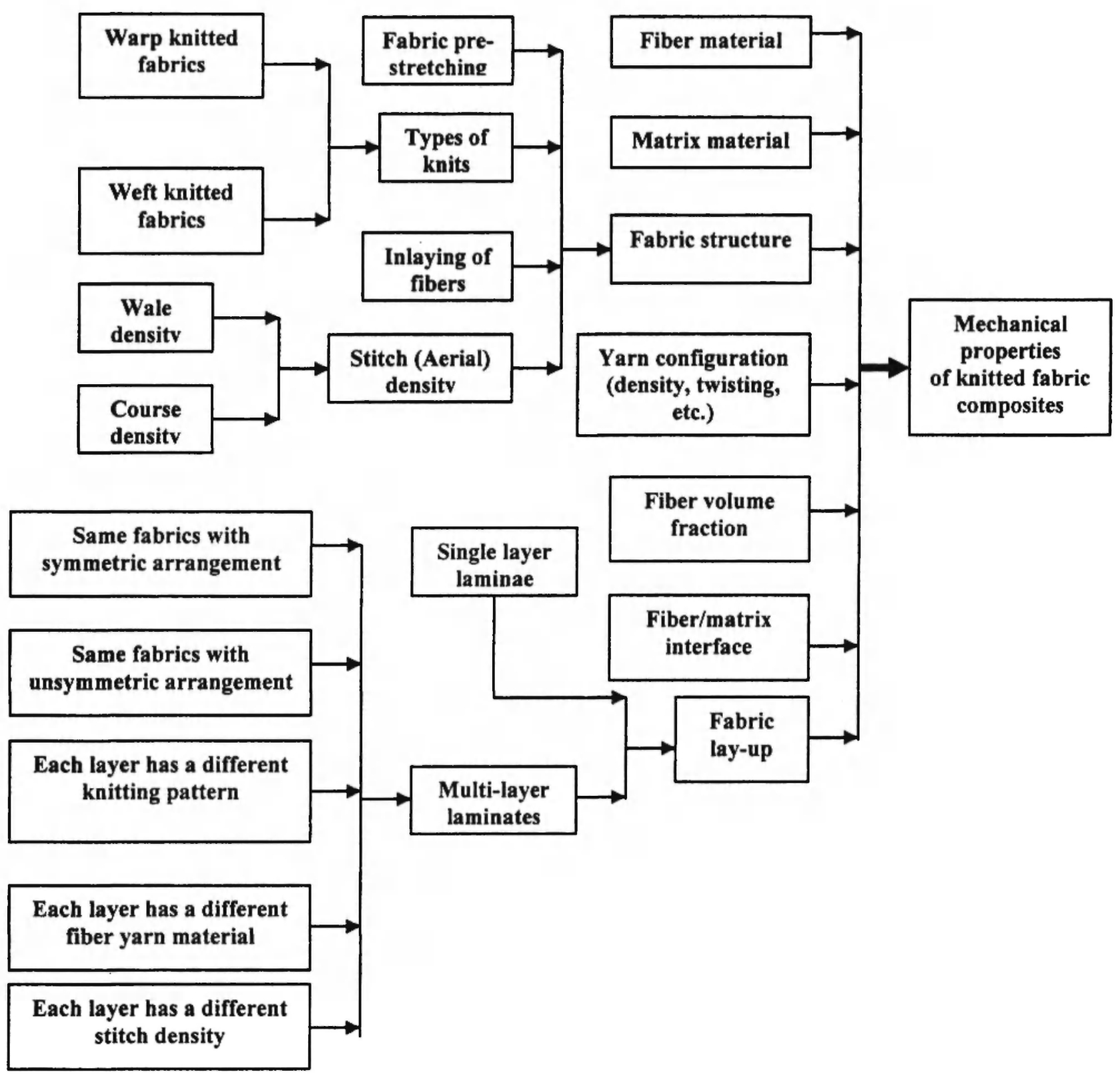

Fig. 16: An overview of various variables that influence the mechanical properties of knitted fabric composites, in which the warp and weft knitted fabrics are further classified in Figs. 17 and 18.

composite is usually small, it is difficult to prepare a testing sample for the composite along the thickness direction. A complete three-dimensional description for the constitutive equations of knitted fabric composites, which requires the material properties in all the three orthogonal planes to be given, would prove impractical using testing results only.
These difficulties make it necessary to theoretically model the mechanical properties of knitted fabric composites. In general, two different modeling approaches exist in the literature. They are numerical and micromechanical. Finite element technique is powerful in performing numerical structural analysis. It has also been applied to predict the tensile properties of 


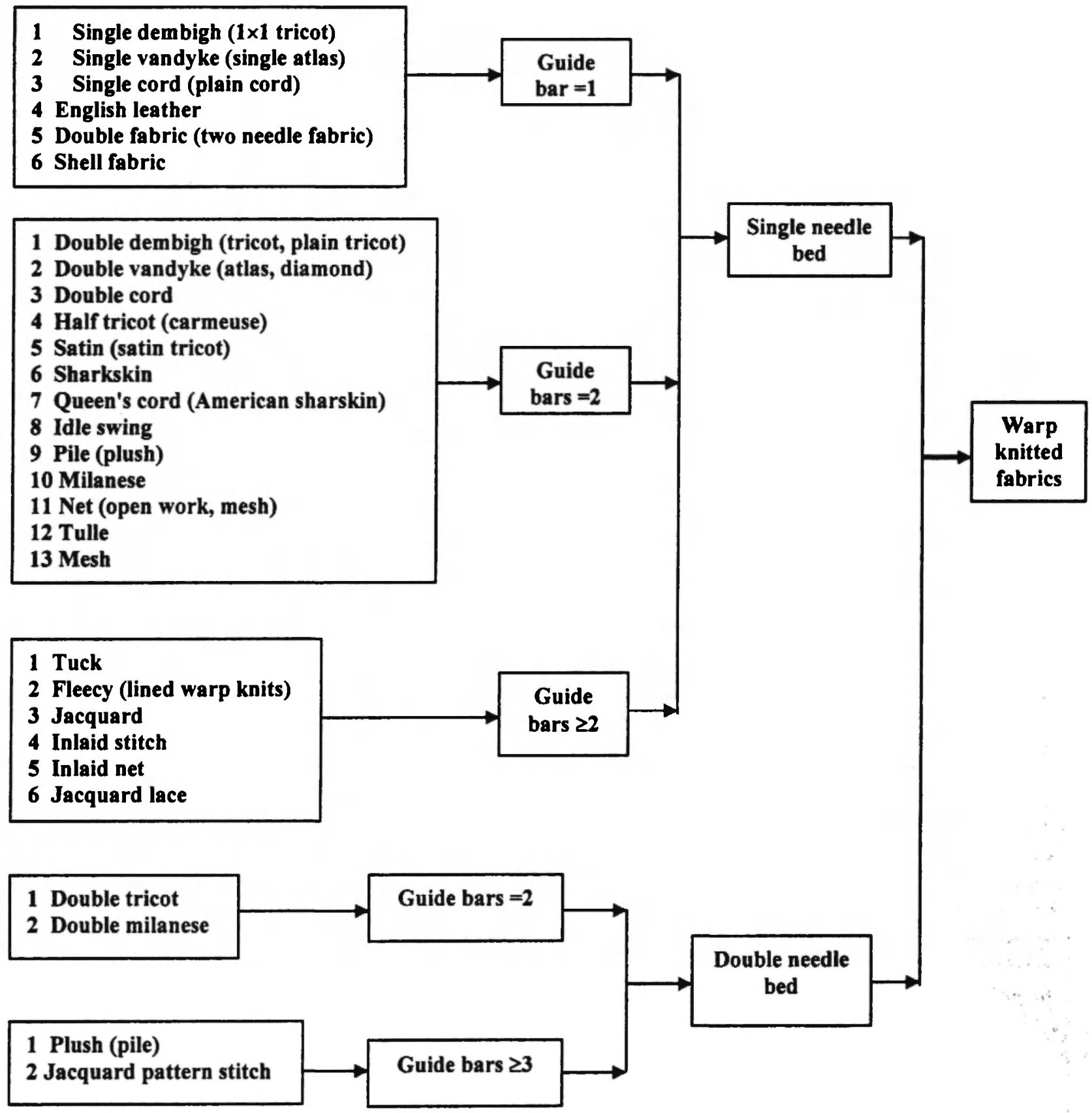

Fig. 17: Classification of warp knitted fabrics

knitted fabric composites with some success /13-17/. However, extensive labour and time cost in mesh generation and computer source has limited this technique in application especially in nonlinear and failure analysis of knitted fabric composites. The purpose of this paper is to review and summarize another approach, i.e., the theoretical modeling approach, based on a recently developed micromechanics model, the Bridging Model $/ 18 /$. The mechanical properties that can be simulated include the elastic modulus, tensile strength, and nonlinear and rubber-elastic response of knitted fabric reinforced thermoset (epoxy) and elastomeric matrix composites. The influence of some variables shown in Fig. 16 on the mechanical behaviors of the knitted fabric composites is also identified. 


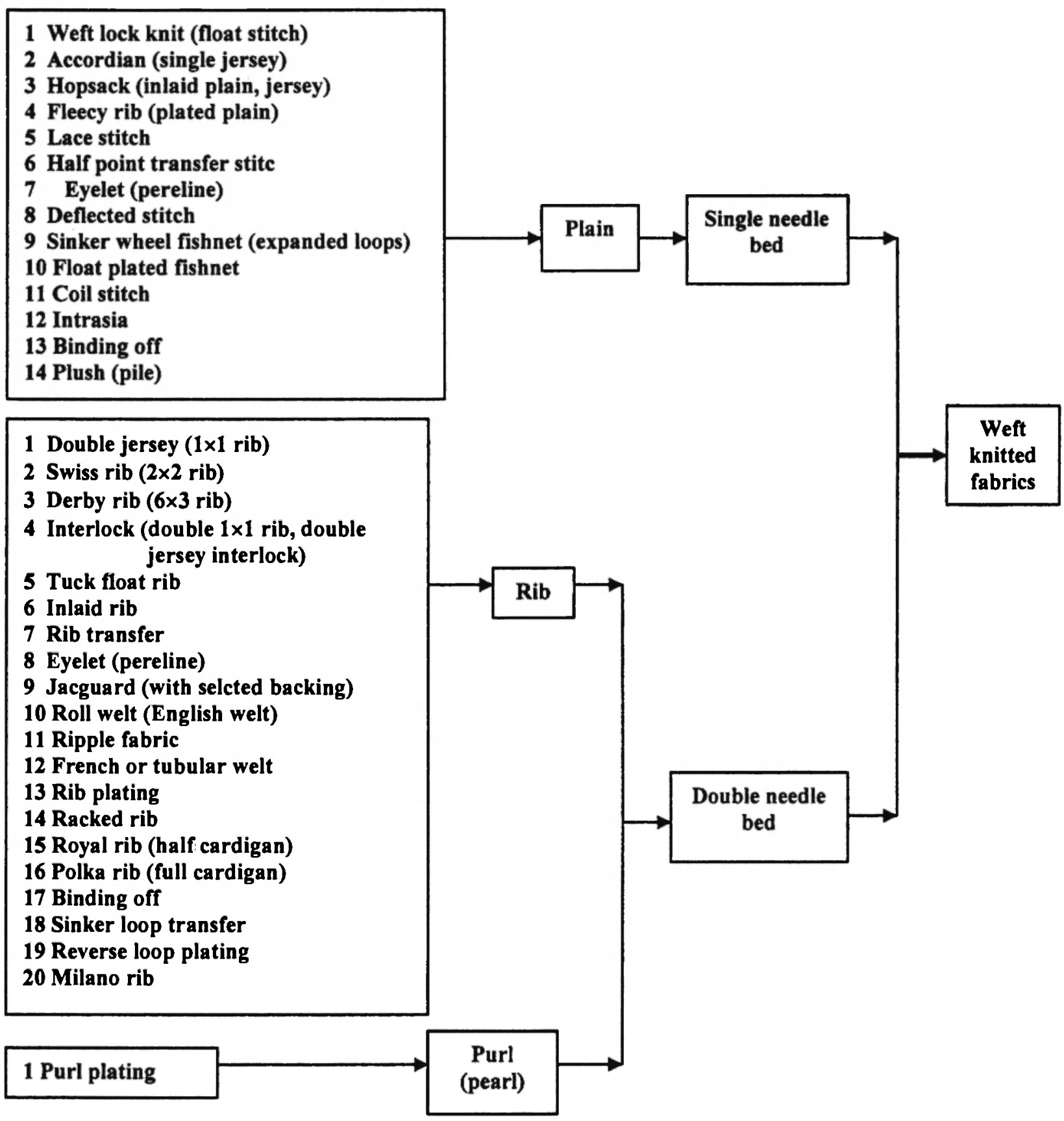

Fig. 18 Classification of weft knitted fabrics

\section{MODELING PROCEDURE}

Three steps are generally observed in the micromechanical simulation of a complicated composite, such as a knitted fabric composite. A flow chart to show the three steps analysis procedure is given below.
In the first step, the composite is subdivided into a number of UD composites. For this purpose, the fiber orientation, or the fabric geometry, in the composite must be identified. The second step of analysis concerns the application of a micromechanical model to all the UD composites to determine their properties. If only the elastic properties of the composites are required, many 


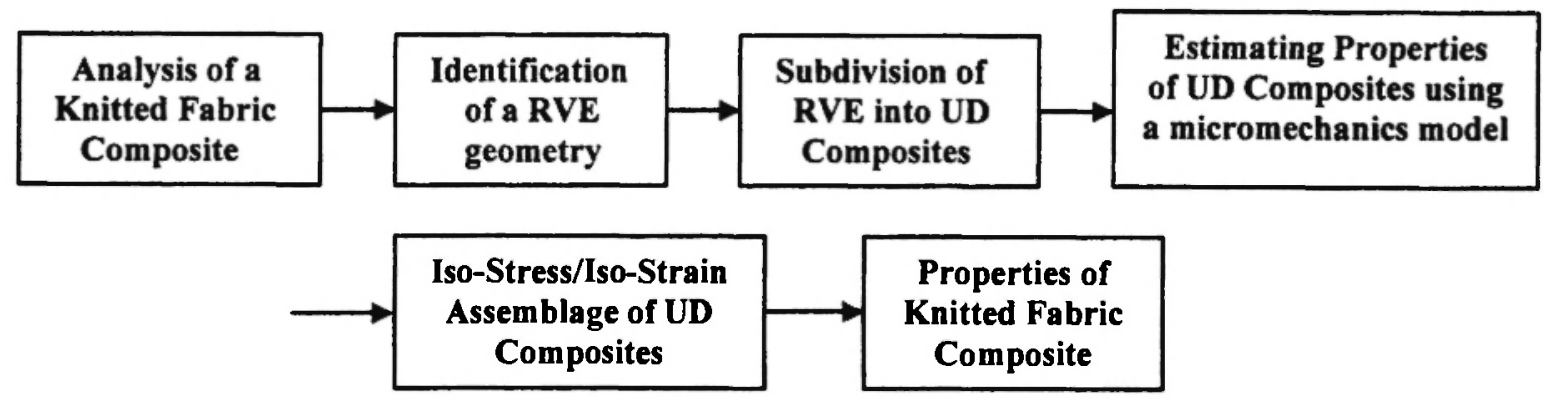

Fig. 19: A flow chart to show analysis procedure for a knitted fabric composite.

such models are available in the literature. If, however, an inelastic/nonlinear analysis and a strength prediction are required, most of these models are not applicable. To address the latter problems, we need to employ a more powerful theory, the bridging micromechanics model $/ 18 /$. The last step of analysis is to assemble the contributions of all the UD composites to obtain the overall property of the knitted fabric composite. Only the first step work, i.e. geometric description for a number of knitted fabric structures, is summarized in the present paper. Detailed elaboration of the other two analysis steps will be given in Part II /19/, whereas simulation results for various thermoset (epoxy) and elastomer matrix based knitted fabric composites (single layer laminae as well as multilayer laminates) will be shown in Part III /20/ of this series of papers.

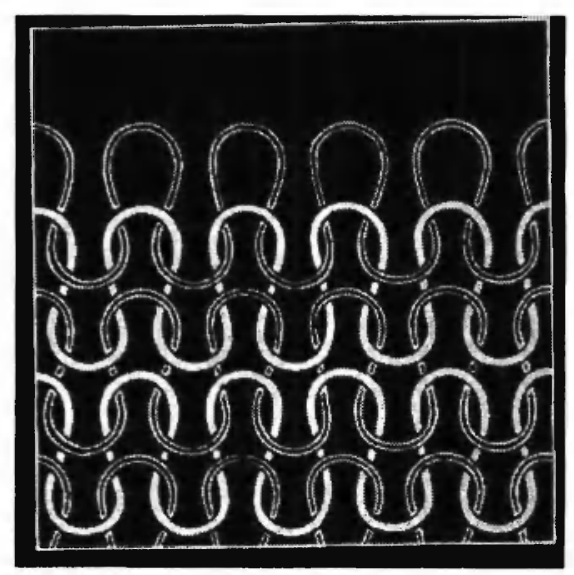

(a)

\section{GEOMETRY OF WEFT KNITTED FABRICS}

Basically, there are two types of knitted fabrics, named warp-knit and weft-knit 121 , respectively, according to their knitting direction. Schematic diagrams of both the knitted fabrics are shown in Fig. 20. If a knitted fabric is constructed from a single yarn or thread and the loops are made horizontally across the fabric, the knitting procedure is called weft knitting, see Fig. 20(a). Alternatively, if at least one thread is supplied to each needle of a complete set of needles and the threads formed into loops which run lengthwise in the fabric, the procedure is called warp knitting, see Fig. 20(b). Most composites studied in this work are made using weft knit reinforcement. But the simulation procedures developed are equally applicable to warp

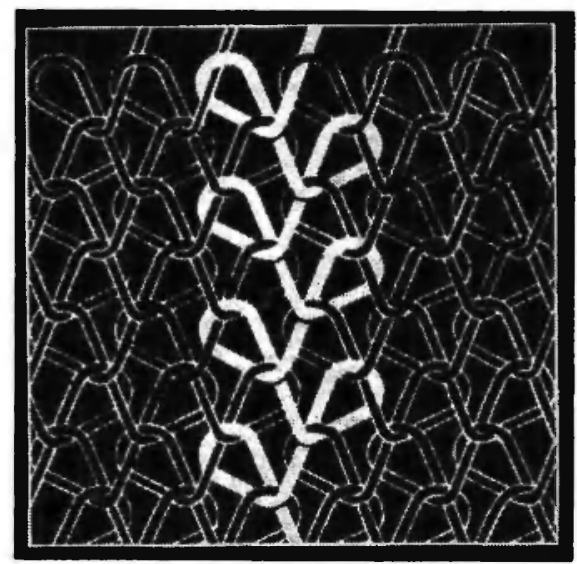

(b)

Fig. 20: Typical (a) weft knitted structure and (b) warp knitted structure 
knitted fabric composites as well. In a weft knitted fabric, the lengthwise rows of loops are known as wales, whereas the rows running across the fabric are referred to as courses.

Although an almost infinite variety of knitting structures exists in the textile industry $/ 1-6 /$, only a limited number of them are being considered for composite reinforcements $/ 7 /$. The reasons are: a) most engineering applications require only simple knit structures and b) unlike textile fibers (e.g. cotton and polyester), some difficulty still exists in forming stiffer reinforcement fibers such as glass and carbon into more complicated knit structures. Typical weft knitted fabrics investigated for engineering applications are summarized in Fig. 21, which can be further classified into four types based on the dimensional (D) arrangement of yarns. Type I fabrics (Fig. 21a) are simple 2D flat knitted fabrics. These fabrics can be cut to the required dimensions and laminated (stacked) in multilayers. Using fully-fashioned knitting machines it is possible to produce 2D fabrics into the net shape of components, which are categorized as type II fabrics (Fig. 21b). Type III fabrics (Fig. 21c) are produced by inserting/introducing straight fiber yarns into the Type I fabrics unidirectionally or bi-directionally. Type IV fabrics (Fig 2Id), also known as sandwich fabrics or 3D hollow fabrics, are produced by binding 2D-face fabrics together using pile yarns $/ 22 \%$. Sometimes these fabrics

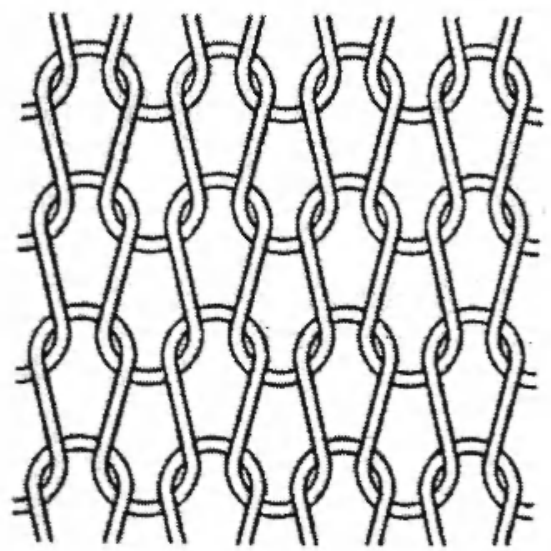

(a) Type I fabric

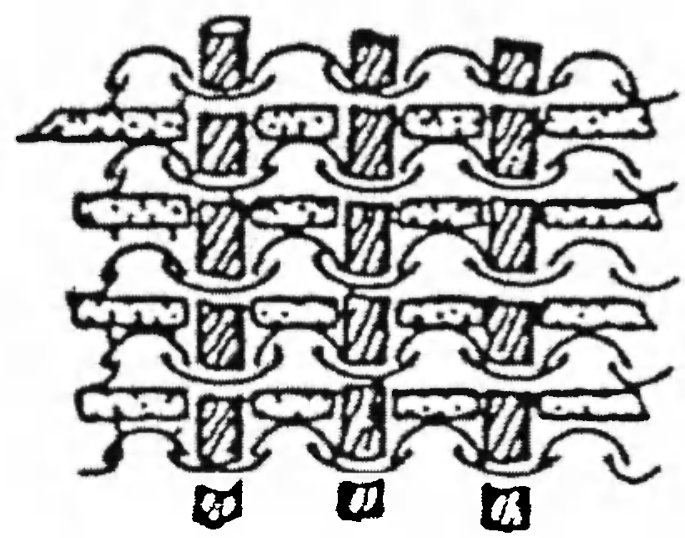

(c) Type III fabric

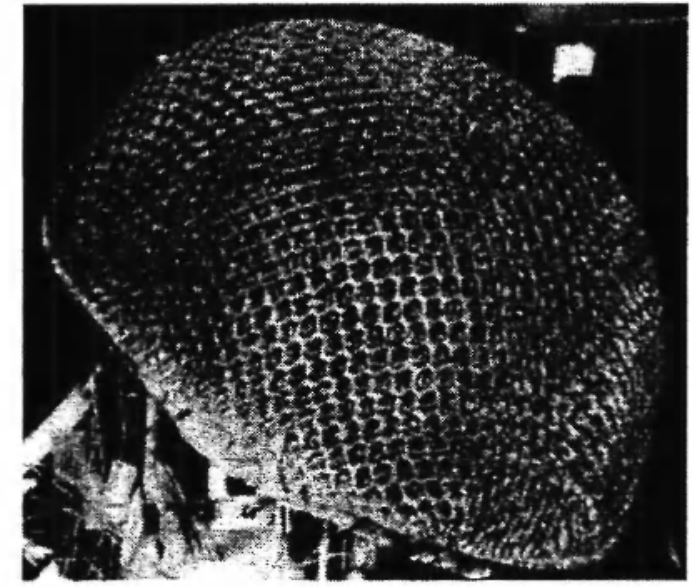

(b) Type II Fabric

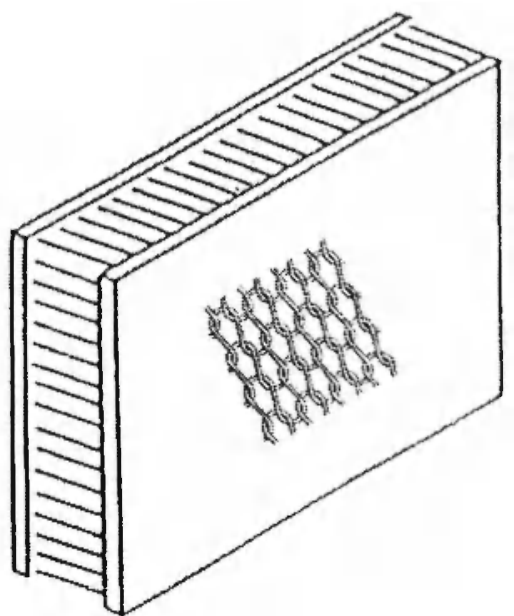

(d) Type IV fabric

Fig. 21: Typical examples of weft knitted fabrics used in engineering applications. 
are referred to as 2.5D fabrics, as the amount of fibers in the thickness direction is less than the fibers in the planar direction of the fabric. They are being considered to achieve optimum design of specific high-performance and damage-tolerant composite structures.

As mentioned earlier, the effective mechanical properties of the knitted fabric composites depend on i) properties of the constituent materials, ii) knit loop structures, and iii) overall fiber volume fraction. Amongst them, the most challenging work is to identify the knit loop structures, as the other two parameters are relatively easy to determine experimentally. This work can be accomplished by characterizing the fabric geometry of a representative volume element (RVE) of the composites. Because of the coherence of the fiber yarns in the knitted fabrics by means of loops, the fiber yarns will generally not change their positions or orientations too much especially in the plane of the fabric when it is impregnated with resin and solidified. This means that we can investigate the fiber yarn geometry using neat fabrics instead of the resinimpregnated fabrics, i.e., fabric composites. Ideally, the fabric geometry should be described by some analytical function in the global coordinates. However, except for the simplest plain weft knit geometry, the yarn positions of which can be specified using the Leaf and Glaskin analytical model $/ 23 /$, it is difficult to find satisfactory functions for other kinds of knitted fabric structures. Measurements have to be performed to determine the yarn positions in general. A frequently used methodology is to evaluate polished cross-sections with an image analysis program and to calculate the fiber orientation distributions by use of the ellipticity of the cut fibers $/ 24,25 \%$. This kind of measurement, however, is usually performed using micrographs such as photographs under a stereomicroscope and high accuracy is difficult to achieve.

Most existing geometric models have been developed for identifying the geometry of type I knitted fabrics, i.e. 2D fabrics, and have been incorporated in simulation of the composite mechanical properties. Some of these models are summarized below.

\subsection{Leaf and Glaskin model for plain knitted fabric}

In 1955, Leaf and Glaskin /23/ developed an analytical model to describe the geometry of a plain weft knitted fabric using three parameters, i.e. the fiber yarn diameter, $d(\mathrm{~cm})$, the fabric loops per unit length in course direction (called wale number), $W$ (loops $/ \mathrm{cm}$ ), and the fabric loops per unit length in wale direction (called course number), $C$ (loops $/ \mathrm{cm}$ ).

From the schematic diagram of a plain weft knitted fabric shown in Fig. 22(a), it is seen that the fabric can be constructed using some basic unit cell, such as that shown in Fig. 22(b). Let us choose the global rectangular axes $\mathrm{O} x$ and $\mathrm{O} y$ to be parallel to the wale and course directions in the fabric plane, respectively. The basic assumption of the Leaf and Glaskin model is that the projection of the central axis of the yarn loop on the fabric plane is composed of circular arcs. This assumption is reasonable as the knit loops are formed during knitting by bending the yarns round a series of equally spaced knitting needles and sinkers.

Suppose that the OQ portion of the loop has a center at $C$ with a total angle $\varphi$, i.e., $O C Q=\varphi$. Let ' $a d$ ' be the radius of the projection of the loop, i.e., the length between $\mathrm{O}$ and $\mathrm{C}$, where $a$ is a constant to be determined. $Q$ is the point at which the central axis of this loop joins the central axis of the loop with a center F. $\mathrm{H}$ and $\mathrm{J}$ are the points at which the yarns of adjacent loops (loops with centers at $\mathrm{C}$ and $\mathrm{B}$ ) cross-over. The angles $\mathrm{OCB}=\psi$ and $\mathrm{HCB}=\phi$. Let $\mathrm{P}$ be any point on the central axis of the loop and the angle of the projection of the loop portion from $\mathrm{O}$ to $\mathrm{P}$ be $\theta, \mathrm{OCP}=\theta$. The coordinates of $\mathrm{P}$ are thus given by $/ 23,261$

$$
\begin{aligned}
& x=a d(1-\cos \theta), \\
& y=a d \sin \theta, \quad 0 \leq \theta \leq \varphi, \\
& z=\frac{h d}{2}\left(1-\cos \left(\pi \frac{\theta}{\varphi}\right)\right)
\end{aligned}
$$

where $h$ is another constant used to represent the maximum height $h d$ (at point $Q$ ) of the central axis 


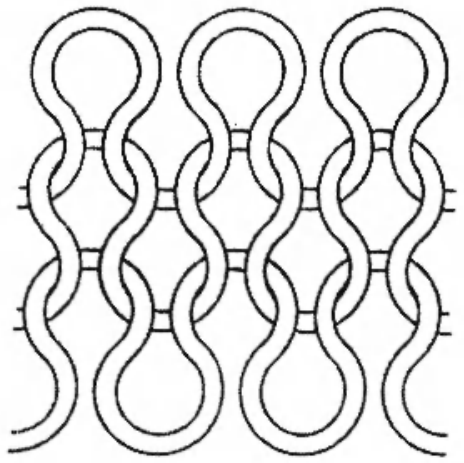

(a)

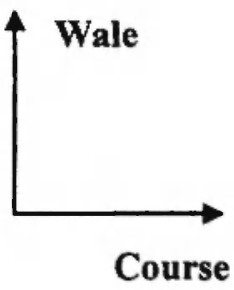

Course

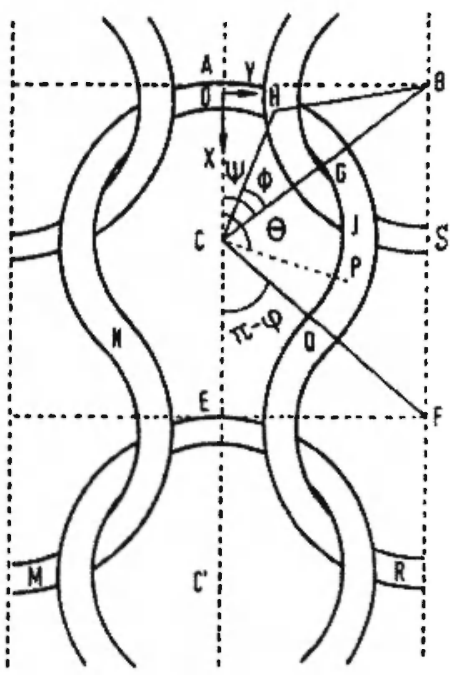

(b)

Fig. 22: Schematic diagrams of (a) idealized plain weft knitted fabric, (b) unit cell.

above the plane of the fabric. The parameters $a, h$, and $\varphi$ in Eq. (1) are determined from the following formulae

$$
\begin{aligned}
& a=\frac{1}{4 W d \sin \varphi}, \\
& x_{0}=\frac{1}{C}-a d(1-\cos \varphi),
\end{aligned}
$$

$\varphi=\pi+\sin ^{-1}\left(\frac{C^{2} d}{\left[C^{2}+W^{2}\left(1-C^{2} d^{2}\right)^{2}\right]^{12}}\right) \cdot-\tan ^{-1}\left(\frac{C}{W\left(1-C^{2} d^{2}\right)}\right)$

$$
\begin{aligned}
& h=\left[\sin \left(\pi \frac{\psi}{\varphi}\right) \sin \left(\pi \frac{\phi}{\varphi}\right)\right]^{-1}, \\
& \psi=\sin \left(\frac{2 a}{2 a-1} \sin \varphi\right), \\
& \phi=\cos ^{-1}\left(\frac{2 a-1}{2 a}\right) .
\end{aligned}
$$

The yarn diameter $d$ can be expressed in terms of the linear density $\left(D_{y}\right)$ of the yarn and packing fraction $(K)$ of fibers in the yarn as

$$
d = 2 \longdiv { \frac { D _ { y } } { 1 0 \pi \rho _ { f } K } } \times 1 0 ^ { - 2 } ( \mathrm { cm } )
$$

where $\rho_{f}$ is the density of fiber $\left(g / \mathrm{cm}^{3}\right)$ and $D_{y}$ is measured in Tex (which is the weight of a yarn having a total length of $1000 \mathrm{~m}$ measured in gram).

From Figure 22(b), it is clear that the orientation of the yam in a knit loop (MNOQR) can be determined by knowing the orientation of the yarn in the portion $O Q$. Thus, we may assume that the $O Q$ portion is an assemblage of a series of straight segments. Let $\left(x_{n-1}, y_{n-}\right.$ $\left.1, z_{11-1}\right)$ and $\left(x_{n}, y_{n}, z_{n}\right)$ be the coordinates of start and end points of the $(n-1)^{- \text {th }}$ yarn segment (see Fig. 23). The orientation of the segment in three-dimensional

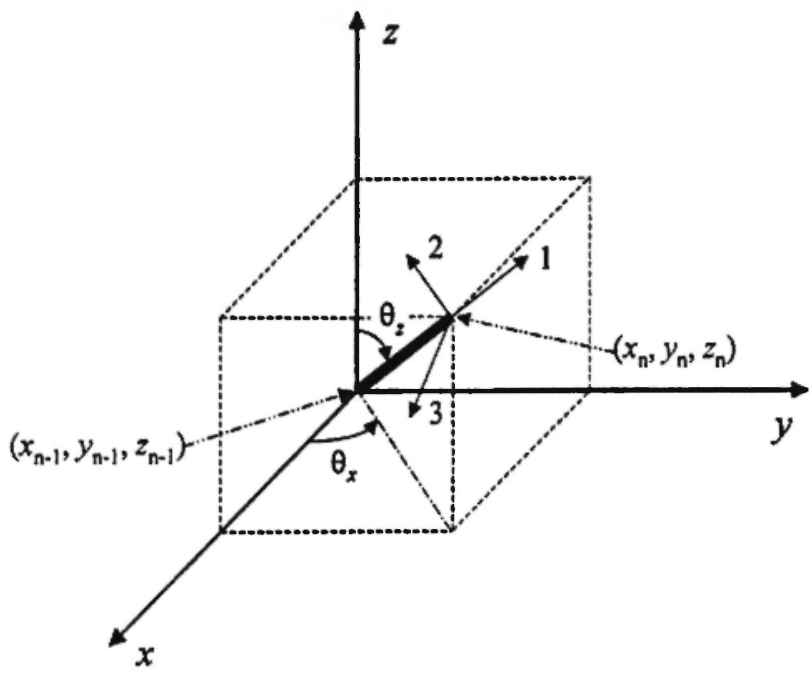

Fig. 23: A yarn segment orientation in the global coordinate system. 
coordinates can be specified using two angles, $\theta_{\mathbf{x}}$ and $\theta_{\mathbf{z}}$, where $\theta_{z}$ is the angle between the $z$ axis and the yarn segment and $\theta_{\mathrm{x}}$ the angle between the $x$ axis and the projected straight line of the segment on the $x-y$ plane. These two angles are important in the geometric analysis. They are determined as

$$
\begin{aligned}
& \theta_{v}=\tan ^{-1}\left(\frac{y_{n}-y_{n-1}}{x_{n}-x_{n-1}}\right), \\
& \theta_{\geq}=\tan ^{-1}\left(\frac{\sqrt{\left(x_{n}-x_{n-1}\right)^{2}+\left(y_{n}-y_{n-1}\right)^{2}}}{z_{n}-z_{n-1}}\right)
\end{aligned}
$$

Equations (4) indicate that only relative coordinates of the yarn are important. Therefore, one can use another unit cell shown in Figure 24(a) to replace the unit cell in Figure 22(b), and take a new coordinate system as shown in Figure 24(b). It is noted that the origin of the new coordinates is shifted by a constant value in the $x$-direction only. As only the relative positions of the yarn segments are required (Eqs. (4)), it is not necessary to explicitly write this constant out. The constant will also be omitted in the following related equations.

The unit cell in Figure 24(a) can be further divided into four identical/symmetric sub-cells. Each sub-cell consists of two impregnated yarns which cross over each other. This sub-cell is known as cross-over model ${ }^{[12]}$, as indicated in Figure 24(b). Using the cross over model, a unit cell can be constructed. Repeating the unit cell in the fabric plane will obviously reproduce the complete plain weft knitted fabric structure. We thus only need to investigate the cross over model, which is taken as a representative volume element of the composite when it is impregnated with the matrix. The coordinates of the first yarn in the model are given by equation (1) with $0 \leq \theta \leq \varphi$. To determine the coordinates of the second yarn, we choose point S (see Fig. 22b) to be the starting point of the second yarn. Noting that $\overline{S B}=\overline{C O}=a d$ and $\overline{O A}=1 /[2 W \tan (\psi)]-a d$, one obtains the coordinates of the points on the second yarn as follows:

$$
\begin{aligned}
& x_{1}^{2 n d}=2 a d-\frac{1}{2 W \tan (\psi)}, \\
& y_{1}^{2 n d}=\frac{1}{2 W}, \\
& z_{1}^{2 n d}=z_{1}^{1 s t}, \\
& x_{n}^{2 n d}=x_{1}^{2 n d}-x_{n}^{1 s t}+x_{0}, \\
& y_{n}^{2 n d}=y_{1}^{2 n d}-y_{n}^{1 s t}, \quad n \geq 2,3, \ldots \\
& z_{n}^{2 n d}=z_{n}^{1 s t}, \quad n
\end{aligned}
$$

where, similarly as for $x^{l s t}$, the same constant has been omitted for $x^{i n d}$. The superscripts $1 s t$ and $2 n d$ refer to the first and the second yarns and the subscript $n$ denotes the discretized point.

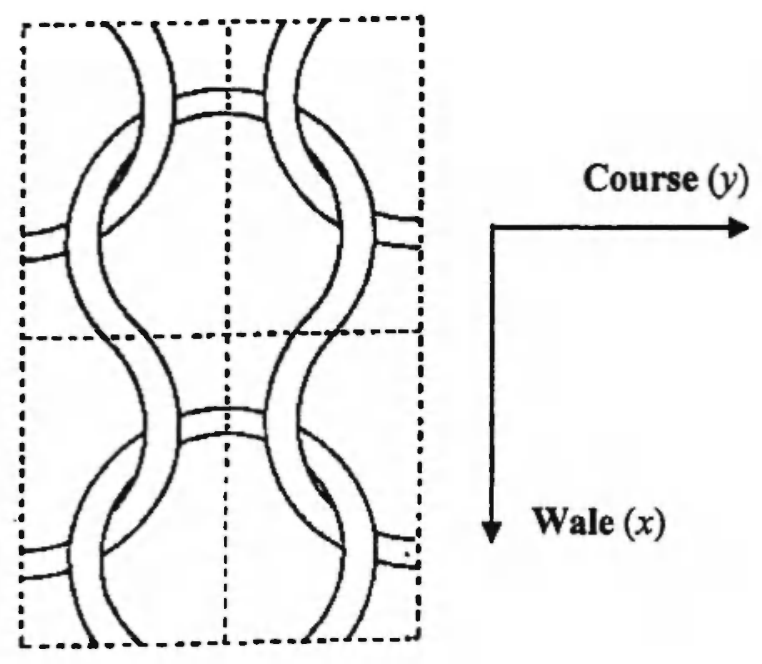

(a)

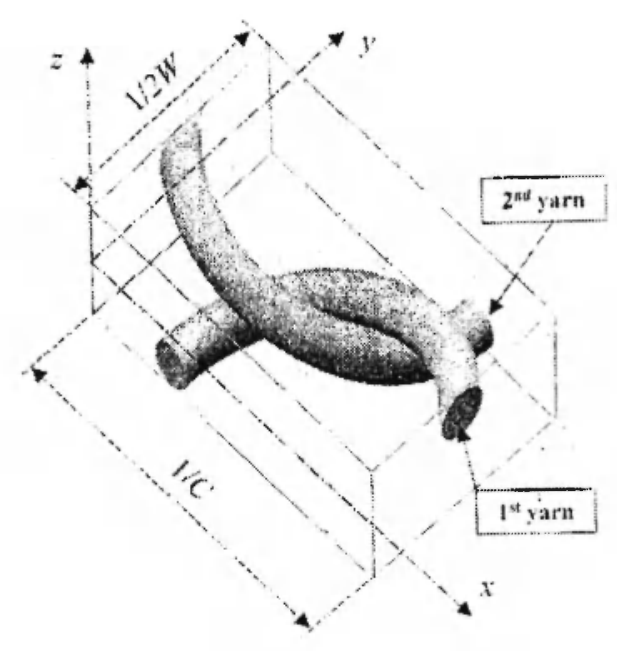

(b)

Fig. 24: Schematic diagram of (a) unit cell and (b) RVE of the composite. 


\subsection{A planar geometry model for an interlock weft knitted fabric $/ 24$ /}

In Ref. $/ 19 /$, a theoretical investigation on the mechanical property of a flexible composite will be addressed. This flexible composite has been made using an interlock weft knitted fabric and polyurethane elastomer matrix on a compression moulding machine. To make the theoretical investigation possible, the interlock fabric geometry must be identified. Due to the unavailability of an analytical model, the interlock fabric geometry has been determined through experimental measurements, the procedure of which is described below.

The interlock weft knitted fabric consists of two layers of plain knits that are interlocked. A schematic diagram of an unprocessed fabric (before embedding in the composite) is shown in Fig. 25. In planar view, it appears like a structure of two layers of plain weft knitted fabrics. In cross section, however, the interlocking structure is apparent. From Fig. 25, one can imagine that the fabric structure is formed by repeating some basic fiber yarn loop and its mirror image. Such a basic loop is three-dimensional (3D) in the unprocessed fabric. However, the geometry of the unprocessed fabric changed after fabrication processing, especially in the thickness direction (the z-direction in Fig. 25). This is due to the high pressure applied during composite fabrication using a compression moulding machine $/ 24 /$ and the molten polyurethane matrix which provides little resistance to the applied load. The composite was thus very thin and the yarn segments in the z-direction were forced to turn towards the $x-y$ plane. Therefore the basic loop was more like a plane curve, as shown in Fig. 26(a).

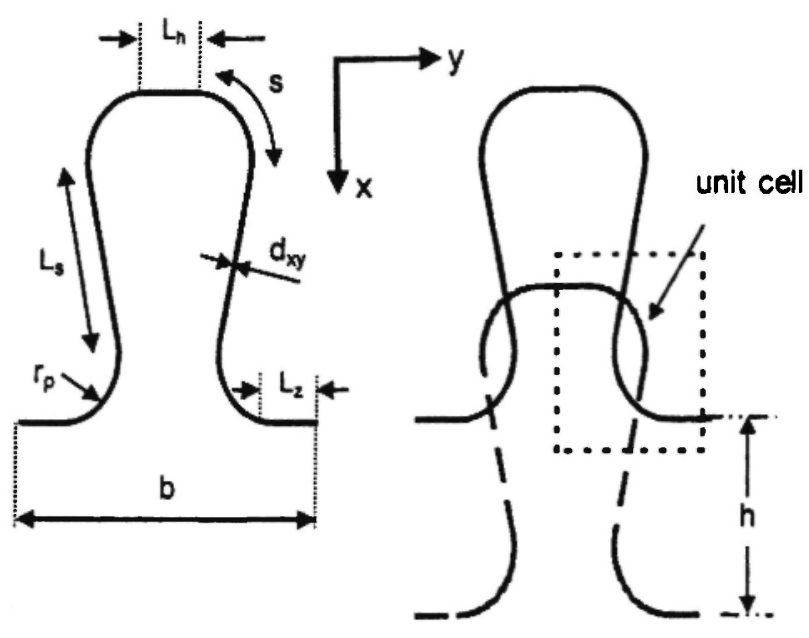

(a)

(b)

Fig. 26: Loop geometry and assigned parameters.

To determine the individual loop parameters shown in the figure, a total number of 23 different loops were measured. They were selected from a microscopic picture of the composite, which was taken at 37 times magnification. The averaged values are given in the first six columns of Table 1 .

The distance $h$ between two adjacent rows of the
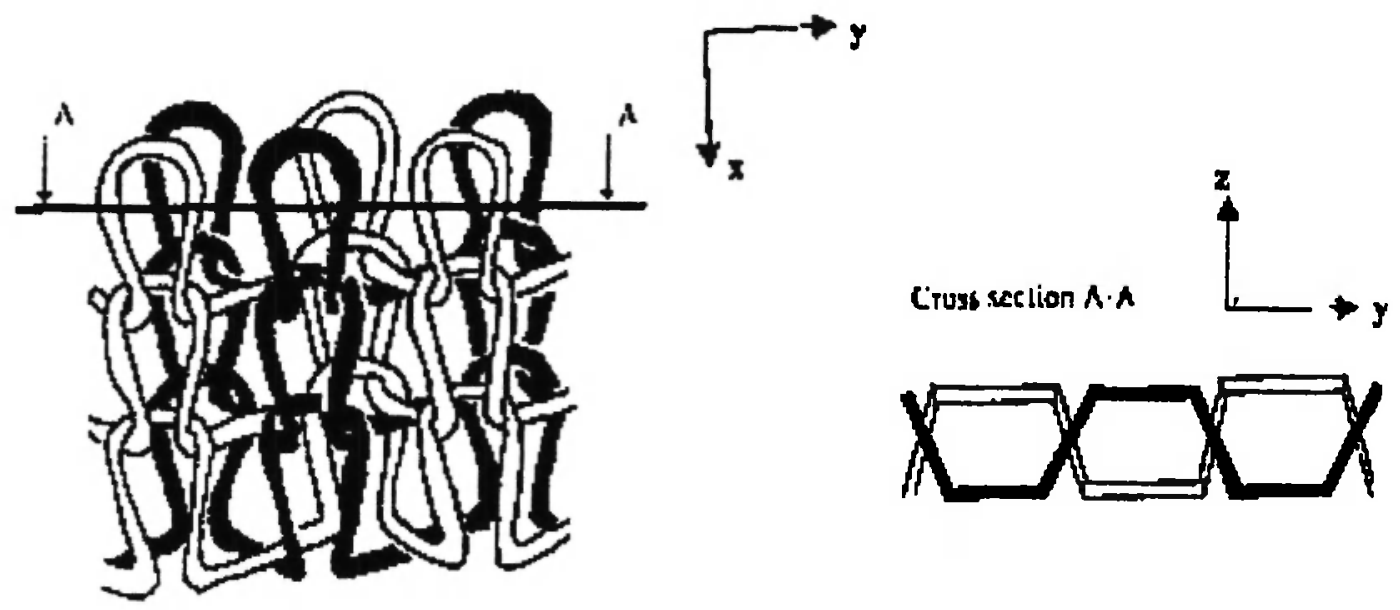

Fig. 25: Schematic interlock knit structure in plain and cross-sectional views. 
Table 1

Averaged Loop Parameters (mm)

\begin{tabular}{|c|c|c|c|c|c|c|c|}
\hline $\mathrm{b}$ & $\mathrm{L}_{\mathrm{z}}$ & $\mathrm{L}_{\mathrm{s}}$ & $\mathrm{L}_{\mathrm{h}}$ & $\mathrm{S}$ & $\mathrm{d}_{\mathrm{xy}}$ & $h$ & $r_{\mathrm{p}}$ \\
\hline 1.20833 & 0.17121 & 0.55443 & 0.22071 & 0.40700 & 0.18038 & 0.65182 & 0.22729 \\
\hline
\end{tabular}

loops was obtained through another measurement. A total number of 1140 fabric loops were counted within a planar area of $913.3 \mathrm{~mm}^{2}$ of the composite, in which there were 30 columns of loops along the $y$-direction and 38 rows along the $x$-direction. As the width of one loop was $1.2 \mathrm{~mm}$ and the height was $1.1 \mathrm{~mm}$, the distance $h$ was found to be $0.6518 \mathrm{~mm}$. Furthermore, by assuming that there was a circular arc at each corner of the loop, the arc radius $r_{p}$ was derived to be $0.2273 \mathrm{~mm}$ and the central angle to be $102.6^{\circ}$.

By adding the above parameters, the measured length of each loop of the fabric is

$$
\mathrm{L}=2\left(\mathrm{~L}_{\mathrm{z}}+\mathrm{L}_{\mathrm{s}}\right)+\mathrm{L}_{\mathrm{h}}+4 \mathrm{~S}=3.3 \mathrm{~mm}
$$

On the other hand, the yarn which built 24 loops in an unprocessed fabric was taken out and its length was measured to be $70 \mathrm{~mm}$, giving a value of $3.2 \mathrm{~mm}$ per loop which is very close to the value given by Eq. (5).

It is difficult to determine the accurate variations of the fiber yarn in the $z$ direction. A Laser Confocal Microscope was used to get the images across the thickness of composite sample. This was possible due to the transparency of the composite and its thinness.
Twenty images were taken from top surface of the composite inward, each being $3 \mu \mathrm{m}$ deep (in the negative $z$-direction) compared to the previous one. Using this procedure, a stack of images was obtained as shown in Fig. 27.

The quality of the images decreased with depth so that only 20 images down to a depth of $-60 \mu \mathrm{m}$ could be taken satisfactorily. Supposing that the fabric composite is symmetric to its midplane, the images can be used to describe the internal structure. Unfortunately, the sharpness of the images is rather low so that they are not suitable for software based processing or analysis. Only basic information could be derived from them, resulting in an estimation of the distribution of the fiber yarns in the $\mathrm{z}$-direction as shown in Fig. 28.

It can be seen that due to the pressure applied during processing, the fiber orientation is nearly $2 \mathrm{D}$. The height of the yarn (in the z-direction) is almost $50 \mu \mathrm{m}$. Comparing this value with the planar dimension of a yarn loop (see Fig. 29), it is reasonable to assume that the amount of yam variation in the z-direction is negligible.

From the fabric, a unit cell, as shown in Fig. 26(b), could be identified. This unit cell will serve as the

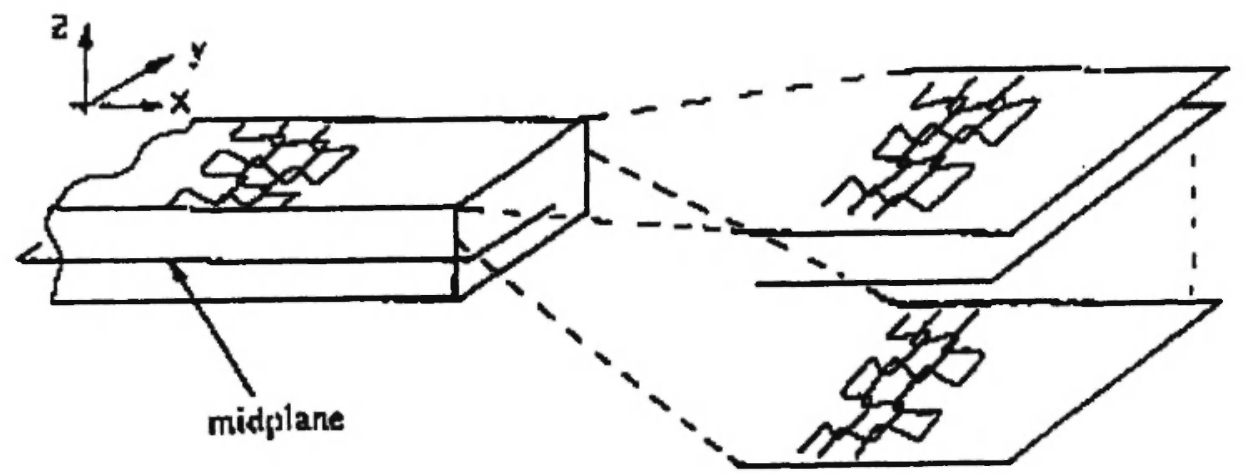

Fig. 27: Slicing the composite to get images using Laser Confocal Microscopy. A total number of 20 images were captured. 


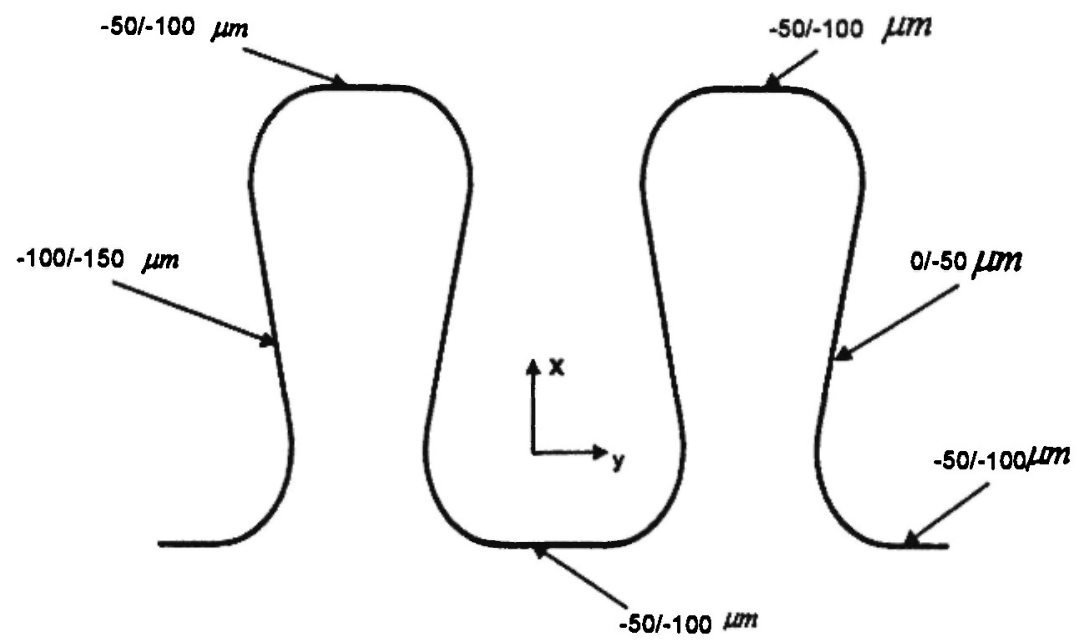

Fig. 28: Location of yarn in z-direction indicated by an upper and lower bounds of continuous loops (belonging to eiţher solid or hollow lines shown in Fig. 25).

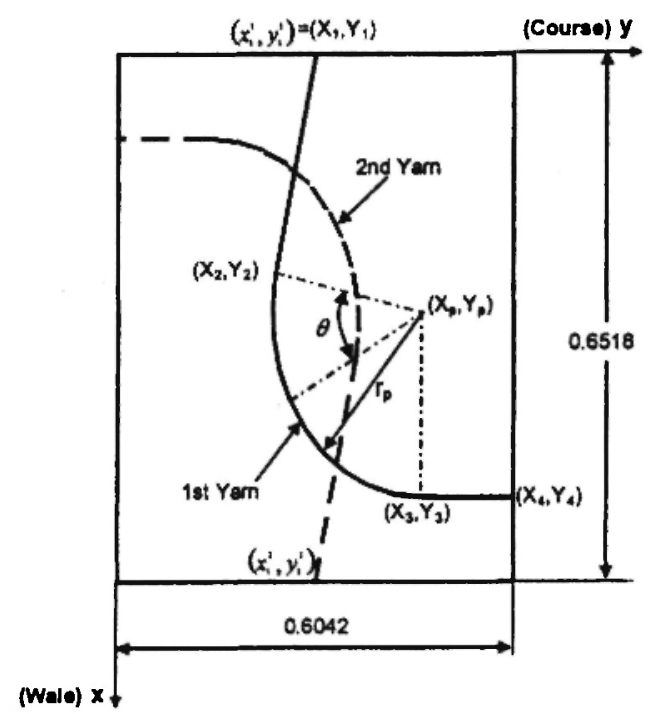

Fig. 29: Unit cell of a textile elastomeric composite and its geometry.

representative volume element (RVE) in later simulation. Table 1 indicates that $L_{z}>\left(L_{h} / 2\right)$, which is attributed to the longer segment of the yarn in the interlock (i.e., the z-) direction. However, the unit cell should exactly represent the overall behavior of the composite. It should also be symmetric in such a way that repeating the unit cell will constitute the whole composite structure, from a physical point of view rather than an exactly geometrical point of view. In this regard, the unit cell was constructed as though $L_{z}$ and $\mathrm{L}_{\mathrm{h}} / 2$ were equal, being $0.14078 \mathrm{~mm}$.

Fig. 29 shows the geometry of the unit cell. There are two yarn loops in the unit cell, which are symmetric to each other. Each yarn consists of two straight lines and a circular arc. The coordinates of the first yarn are thus derived as:

on straight line:

$x_{i}^{1 s t}=\mathrm{X}_{1}+\mathrm{t}\left(\mathrm{X}_{2}-\mathrm{X}_{1}\right), y_{i}^{1 s t}=\mathrm{Y}_{1}+\mathrm{t}\left(\mathrm{Y}_{2}-\mathrm{Y}_{1}\right), 0<\mathrm{t}<1$,

or: $x_{i}^{1 s t}=\mathrm{X}_{3}+\mathrm{t}\left(\mathrm{X}_{3}-\mathrm{X}_{4}\right), y_{i}^{\mathrm{ist}}=\mathrm{Y}_{3}+\mathrm{t}\left(\mathrm{Y}_{4}-\mathrm{Y}_{3}\right), 0<\mathrm{t} \leq 1(6.2)$ on circular arc:

$x_{i}^{1 s t}=\mathrm{X}_{\mathrm{p}}+\mathrm{r}_{\mathrm{p}} \sin \left(\theta-12.6^{\circ}\right), y_{i}^{1 s t}=\mathrm{Y}_{\mathrm{p}}-\mathrm{r}_{\mathrm{p}} \cos \left(\theta-12.6^{\circ}\right)$,

$$
0^{\circ}<\theta<102.6^{\circ}
$$

where the undefined parameters are: $X_{1}=0.0000$, $\mathrm{X}_{2}=0.2700, \quad \mathrm{X}_{3}=0.5414, \quad \mathrm{X}_{4}=0.5414, \quad \mathrm{X}_{\mathrm{p}}=0.3141$, $Y_{1}=0.3021, Y_{2}=0.2416, Y_{3}=0.4635, Y_{4}=0.6042$, and $Y_{p}=0.4635$. All these parameters as well as those in Fig. 29 are in $\mathrm{mm}$.

The coordinates of the second yarn are simply given by:

$$
x_{i}^{2 n d}=0.6518-x_{i}^{1 s t}, \quad y_{i}^{2 n d}=0.6042-y_{i}^{1 s} .
$$




\subsection{Approximation to Milano rib knitted fabric $127 /$}

We have seen that it is usually difficult and very time-consuming to accurately identify the yarn orientations through experiments in a knit structure except for the plain knit. Such identification becomes more impracticable if different stitch densities are applied to the fabric. On the other hand, the plain knit geometry constitutes a basic pattern of other weft knit fabrics. Therefore, geometrical description for other types of weft knit structures could be achieved/approximated by combining different plain knit loops, namely, by using combinations of the Leaf and Glaskin model formulae. In this sub-section, such an approximation is illustrated using a weft knit Milano rib knit fabric $/ 27 \%$.

The Milano rib knit fabrics under consideration were made on a V-bed knitting machine using combined $2 \times 68$ Tex E-glass fiber yarns $128,29 /$. A microphotograph of a Milano rib knit fabric is shown in Fig. 30, whereas a schematic diagram of an idealized Milano fabric in the planar view is graphed in Fig. 31. The Milano rib structure affords good control on the natural extensibility. In each complete repeat of the Milano structure pattern, three fiber yarn courses (Fig. 31) are recognized. They are two rows of single jerseys (courses 2 and 3 in Fig. 31), knitted on two separate sets of needles, and a row of $1 \times 1$ rib course (course 1 in Fig.
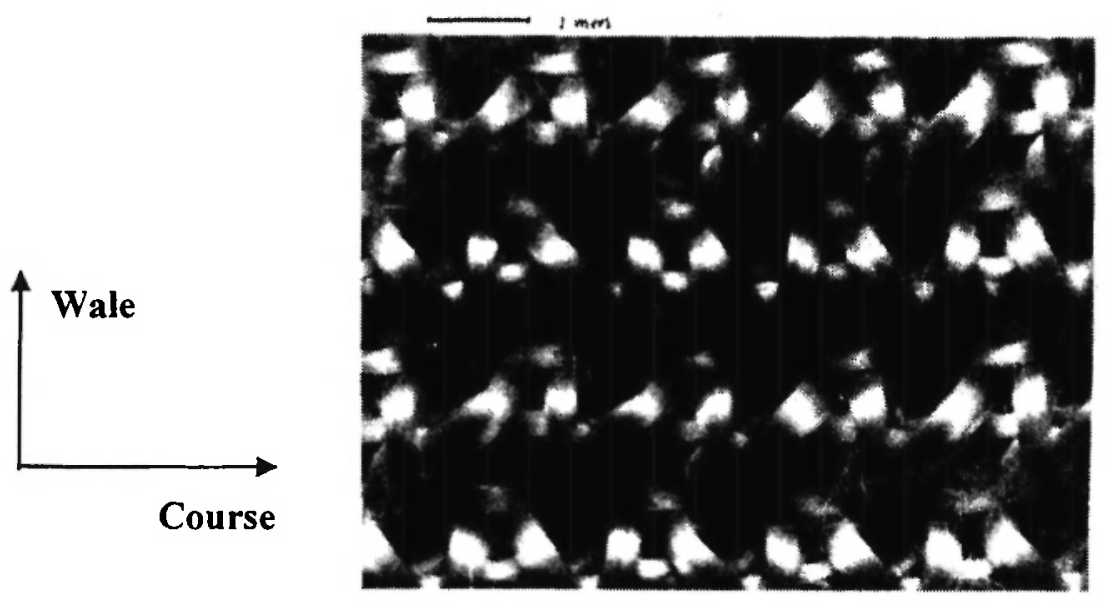

Fig. 30: Micro-photograph of a Milanao rib knitted fabric.

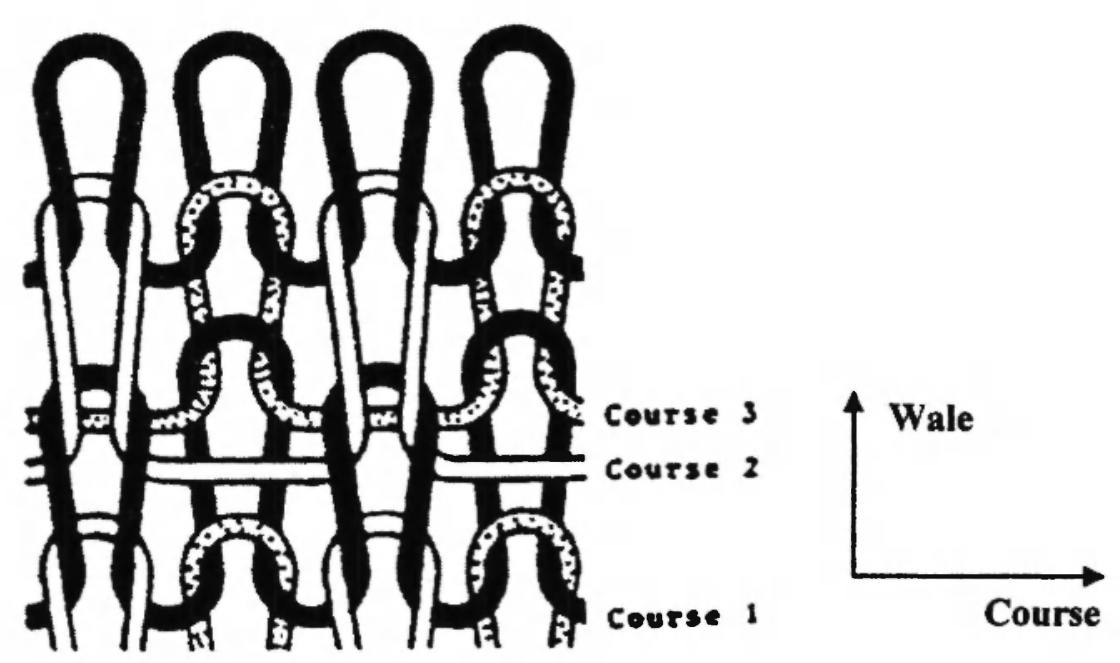

Fig. 31: Schematic diagram of an idealized Milano rib knit architecture. 
31), which holds the two single jerseys together. It is noted that within the two single jerseys, one is the plain or face loop (the course 2), and another is the back loop (the course 3 ). Consequently, the resultant fabric is balanced and relatively stable $/ 28,29 \%$. The face and back surfaces are identical in construction and hence, in appearance. Because of the effect of the stiffness of the yarns used in the fabrics, the yarn configuration of the idealized Milano fabric is distorted to that shown in Fig. 30 , which is quite complicated in nature.

Geometrically, a back loop (indicated as "back wale" in Fig. 32a) can be obtained by a plain loop through a symmetric transformation with respect to the fabric plane. If, however, only the yarn orientation in the fabric plane (planar geometry) is important, both loops can be considered as identical (having identical planar coordinates). Moreover, the $1 \times 1$ rib stitch fabric (Fig. 32a) is made of the same type of loop as the plain stitch. Whereas every loop in the plain structure is drawn from the back to the face, the loops of the same course in the rib structure are drawn to both sides of the fabric. Some loops are knitted to the front (face wales) and the others to the back (back wales), as shown in Fig. 32(b). A face wale is composed entirely of face loops and a back wale entirely of back loops. The appearance of the face and the back are identical. If we focus on planar geometry, the rib knit fabric can be treated as an equivalent plain knit fabric, as shown in Fig. 22a. Therefore, the planar geometry of the Milano fabric can be approximated using two plain weft knits, one for the rib course and another for the plain/back course. This treatment can simplify the analysis very much.

For the Milano fabric, the repeated numbers of patterns in wale and course directions are easily identified through measurement or from knitting parameters. They are called wale and course densities, i.e., the course number $(C$, loops $/ \mathrm{cm}$, corresponding to wale density) and the wale number ( $W$, loops $/ \mathrm{cm}$, corresponding to course density), respectively. Further, the loop lengths of plain/back and rib courses can also be measured by taking out the corresponding yarns from the fabric. The last parameter easily obtainable is the whole fiber content. When the Milano fabric is reinforced in epoxy matrix, the overall fiber volume fraction of the resulting composite can be measured through resin-digestion $/ 30$ / or some other technique. In the latter calculation, two different Milano fabrics as well as one $|\times|$ rib knit fabric reinforced epoxy composites will be considered. The geometric details of these fabrics/composites, taken from Ref. 129/, are summarised in Table 2.

Using the geometric parameters given in Table 2, the Milano fabrics can be approximately constructed by repeating some plain stitch loops, if the fabric planar

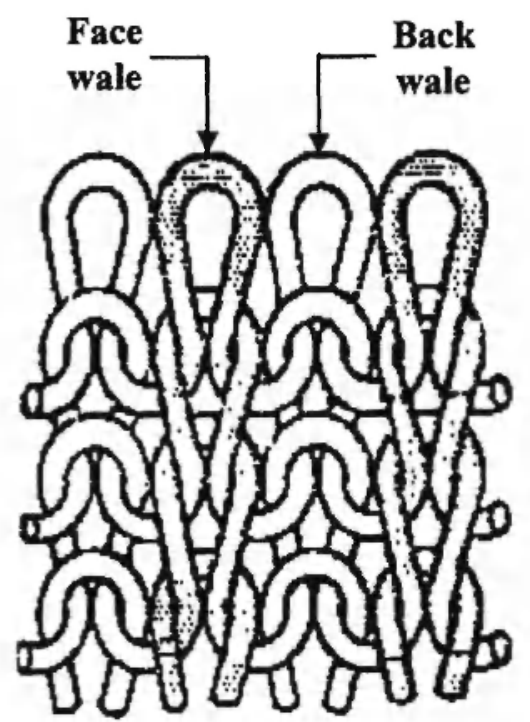

(a)

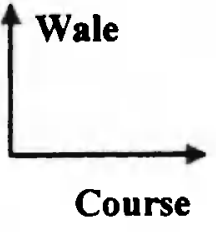

Fig. 32: Schematic diagram of a rib knitted fabric: (a) planar view, (b) rib knitting. 
Table 2

Geometric details fabrics/composite panels

(composite panel thickness $=3.0 \mathrm{~mm}$, yarn diameter $=0.274 \mathrm{~mm}$ )

\begin{tabular}{|c|c|c|c|c|c|c|}
\hline \multirow[b]{2}{*}{$\begin{array}{l}\text { Fabric } \\
\text { Type }\end{array}$} & \multicolumn{2}{|c|}{ Loop density (cycle/cm) } & \multicolumn{2}{|c|}{ Loop length (mm) } & \multicolumn{2}{|c|}{ Panel details } \\
\hline & $\begin{array}{c}\text { Course } \\
\text { density }(W)\end{array}$ & $\begin{array}{l}\text { Wale density } \\
\text { (C) }\end{array}$ & Plain course & Rib course & $\begin{array}{l}\text { Fabric } \\
\text { layers }\end{array}$ & $\begin{array}{c}\text { Overall fiber } \\
\text { volume fraction } \\
\left(V_{1}\right)\end{array}$ \\
\hline Milano, Ml & 8.8 & 4.5 & 5.8 & 6.6 & 6 & 0.521 \\
\hline Milano, M3 & 9.2 & 4.7 & 6.2 & 6.5 & 6 & 0.533 \\
\hline Rib, R3 & 10.2 & 3.92 & - & 6.2 & 6 & 0.529 \\
\hline
\end{tabular}

geometry is of primary concern. In the present study, the row of rib course is constructed by an equivalent plain stitch, as shown by lines of small triangular dots in Fig. 33 (there remain only these lines for the R3 rib fabric). The stitch course density, i.e., the wale number $(W)$, is the same as that of the Milano fabric. For example, for the M3 Milano fabric listed in Table 2, the wale number is 9.2 (cycle/cm). The stitch wale density, or the course number $\left(C_{1}\right)$, can be determined by using the loop length of the rib course (being 6.5 for the M3 fabric). From the Leaf and Glaskin model for plain fabric geometry, the calculated course number is: $C_{1}=5.9$ (cycle/cm). It is noted that the present yarn diameter is: $d=0.274 \mathrm{~mm}$, which is obtained using yarn linear density of $2 \times 68=136 \mathrm{Tex}$, fiberglass mass density of $2.54 \mathrm{~g} / \mathrm{cm}^{3}$, and 0.907 yarn packing density $/ 31 /$. For the plain and back courses, i.e., courses 2 and 3 shown in Fig. 31, it is assumed that they have the same stitch density. The geometry of both is also described by the Leaf and Glaskin model. The wale number of these courses is the same as that of the rib course. However, the course number, $C_{2}$, is different, which should be determined using the measured loop length of the plain course (6.2mm for the M3 fabric). It is to be noted that the Milano plain loop length is not equal to the loop length obtained using the Leaf and Glaskin model. As can be seen from Fig. 31, the measured loop length of the plain/back course must have included the contribution of a straight-line segment which connects two adjacent plain/back loops in between a rib loop. Hence, the back calculated $C_{2}$ for the M3 fabric is $\mathbf{8 . 4}$ (cycle $/ \mathrm{cm}$ ). Using the parameters $W, C_{2}$, and $d$, the Leaf

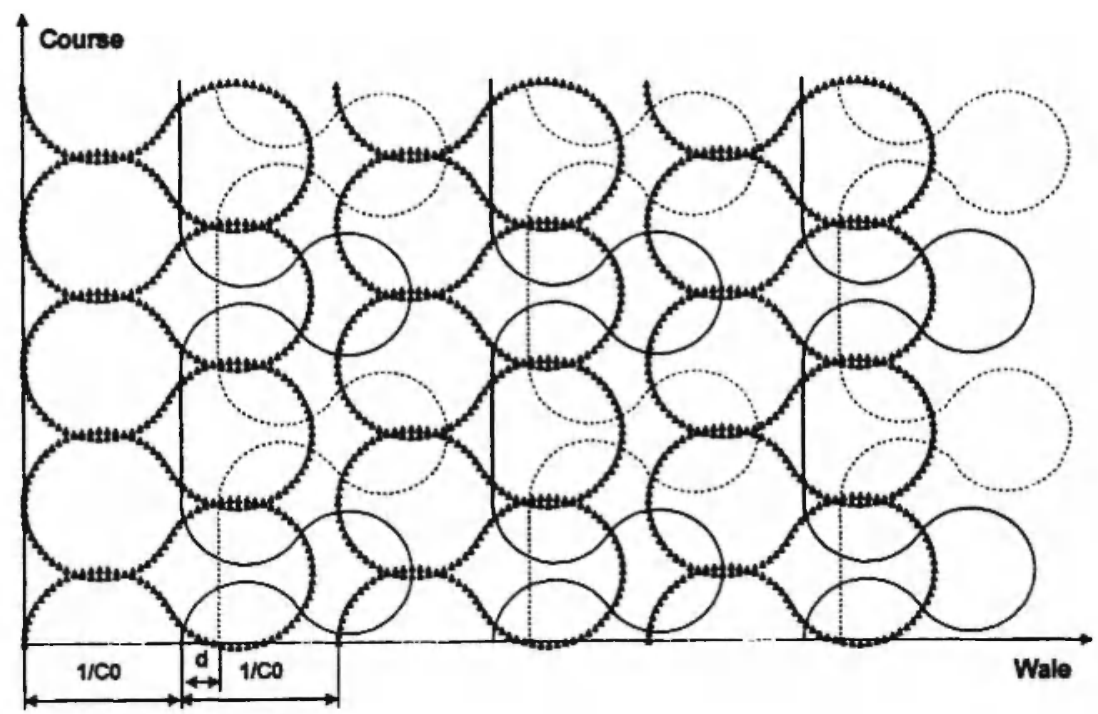

Fig. 33: An idealized Milano rib knit fabric. 
and Glaskin model gives the plain course and back course as the solid and broken lines plotted in Fig. 33, respectively.

There remain two parameters, i.e., the distances between the course 1 (rib course) and course 3 (back course) and the course 2 (plain course) and course 3 in the wale direction, to be determined. The distance between the course 2 and course 3 is assigned to be $d$, the yarn diameter. This means that the plain and back courses are contacted to each other in the fabric. The distance between course 1 and course 3 (denoted by $1 / C_{0}$ in Fig. 28), however, is determined using the condition that the resulting fiber volume fraction should be equal to the measured one. For the M3 fabric, this fraction is 0.533 (Table 2), from which the calculated $C_{0}$ is $8.5(\mathrm{cycle} / \mathrm{cm})$. It is noted that the repeated number of the Milano structure patterns in the wale direction (Wale density) is approximated as $8.5 / 2=4.25$ (cycle $/ \mathrm{cm}$ ), which is close to the measured Wale density, 4.7 (cycle/cm), see Table 2. Parameters of the plain weft stitch loops, which are used to approximate the Milano as well as the rib structures of Table 2 , are summarised in Table 3. The unit cell geometry, using approximated plain stitches, for the M3 Milano fabric is shown in Fig. 34. This unit cell, when it is impregnated with the epoxy resin, serves as the representative volume element (RVE) for the composite stiffness and strength calculation in Part ll of this series of papers.

Table 3

Approximated stitch details using plain weft knits

\begin{tabular}{|c|c|c|c|c|c|c|c|c|}
\hline \multirow{2}{*}{$\begin{array}{c}\text { Fabric } \\
\text { type }\end{array}$} & \multicolumn{2}{|c|}{ Milano stitch } & \multicolumn{3}{c|}{ Rib course stitch } & \multicolumn{3}{c|}{ Plain/Back course stitch } \\
\cline { 2 - 9 } & $\begin{array}{c}W \\
\text { (cycle/cm) }\end{array}$ & $\begin{array}{c}C^{*} \\
\text { (cycle/cm) }\end{array}$ & $\begin{array}{c}W \\
\text { (cycle/cm) }\end{array}$ & $\begin{array}{c}C_{1} \\
\text { (cycle/cm) }\end{array}$ & $\begin{array}{c}\text { Loop } \\
\text { length }\end{array}$ & $\begin{array}{c}W \\
\text { (cycle/cm) }\end{array}$ & $\begin{array}{c}C_{2} \\
\text { (cycle/cm) }\end{array}$ & Loop length \\
\hline M1 & 8.8 & 4.47 & 8.8 & 6.8 & $6.58 \mathrm{~mm}$ & 8.8 & 10.4 & $5.79 \mathrm{~mm}$ \\
\hline $\mathrm{M} 3$ & 9.2 & 4.25 & 9.2 & 5.9 & $6.49 \mathrm{~mm}$ & 9.2 & 8.4 & $6.18 \mathrm{~mm}$ \\
\hline
\end{tabular}

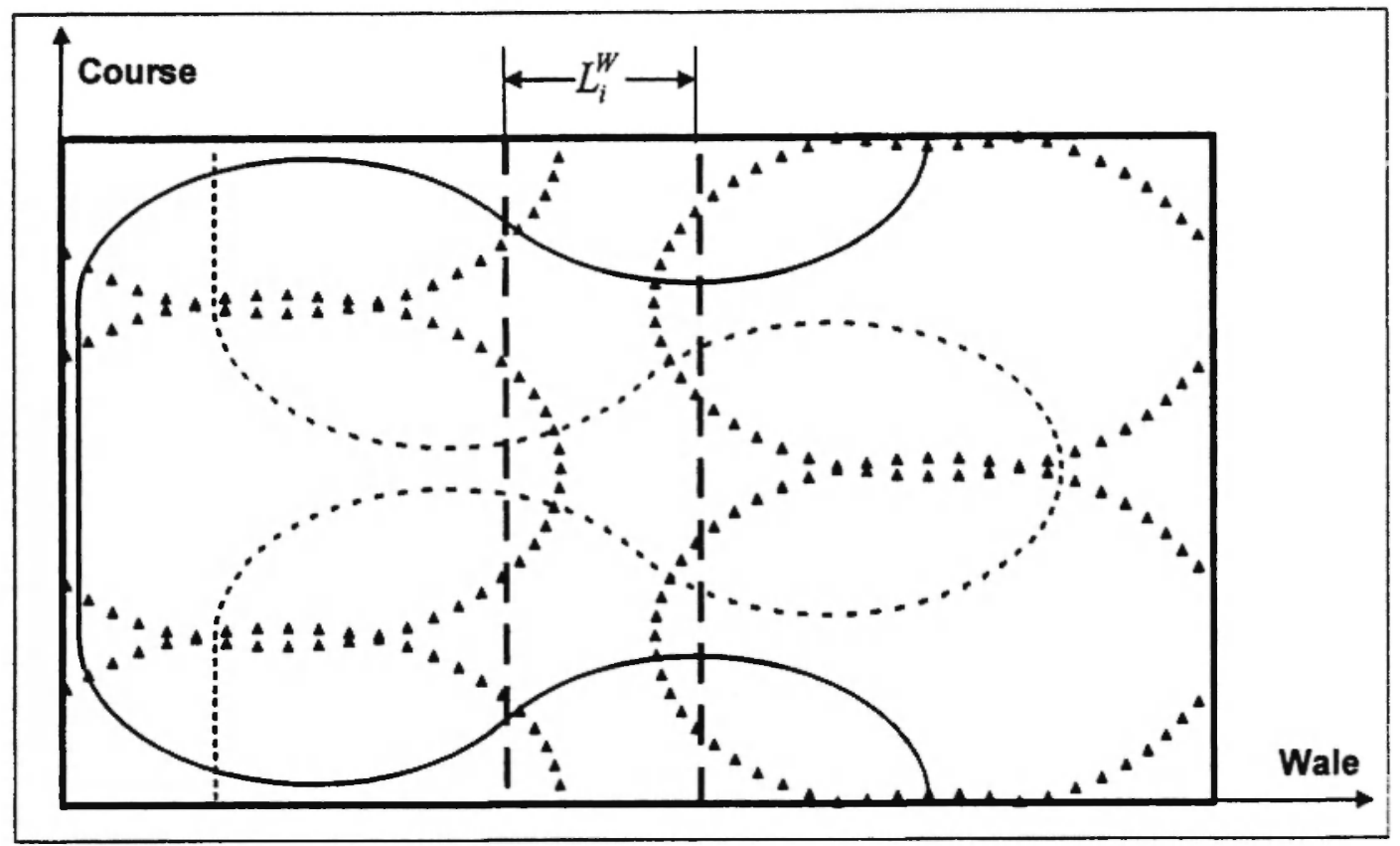

Fig. 34: Unit cell geometry of the M3 Milano fabric used in analysis. 


\section{CONCLUSION}

Having performed systematically a theoretical investigation into various mechanical properties of knitted fabric reinforced composites, our intension is to review and summarize our work in a three-part paper. The present part focused on an overview of the modeling as well as the geometric description involved. In the attempt to model the mechanical properties of knitted fabric composites, identification of the fabric geometry is a critical issue. For this purpose, three ways of approach are generally employed: a) theoretical description, b) experimental identification, and c) numerical approximation. These approaches have been illustrated in the paper by considering a plain knit, an interlock knit, and a Milano rib knit respectively. Detailed simulation procedures, experimental evidences, correlation between theoretical results and experiments, and parametric studies for various kinds of knitted fabric composites will be reported in the remaining two parts of the paper.

\section{REFERENCES}

1. Leong, K. H., Ramakrishna, S., Huang, Z. M., and Bibo, G. A., 2000, The Potential of Knitting for Engineering Composites, Composite A, Vol. 31, No. 3, pp. 197-220.

2. Hearle, J. W. S., 1995, Textile for Composites-Part II: Mutiple Dimensions and Directions, Textile Horizons, Vol. 15, No. 1, p. 11.

3. Lau, K. W. and Dias, T., 1994, Knittability of High-Modulus Yarns, J. Text. Inst., Vol. 85, No. 2, pp. 173-190.

4. Mayer, J., Wintermantel, E., Angelis, F. De, Niedermeier, M., Buck, A., and Flemming, M., 1991, Carbon Fiber Knitting Reinforcement (KCF) of Thermoplastics: A Novel Composite, Proc. of Euromat, Cambridge, pp. 18-26.

5. Huang, Z. M. and Ramakrishna, S., 2000, Micromechanical modeling approaches for the stiffness and strength of knitted fabric composites: A review \& comparative study, Composite A, Vol. 31, No. 5, pp. 479-501.

6. Huysmans, G., Verpoest, I., and Houtte, P. Van,
1998, A Poly-inclusion Approach for the Elastic Modelling of Knitted Fabric Composites, Acta Mater., Vol. 46, pp. 3003-3013.

7. Hamada, H., Ramakrishna, S. and Huang, Z. M., Knitted Fabric Composites (Chapter 6), in ThreeDimensional Textile Reinforcements, A. Miravete ed., Woodhead Publishing Ltd., 1999, pp. 180-216.

8. Ramakrishna, S., Huang, Z. M., and Yew N. M., 1999, Development of a Novel Flexible Composite Material, J. of Mater. Processing Tech., Vol. 8990, pp. 473-477.

9. Bini, T. B., Ramakrishna, S., Huang, Z. M., and Lim, C. T., 2001, Structure-Tensile Property Relationship of Knitted Fabric Composites, Polymer Composites, Vol. 22, No. 1, pp. 11-21.

10. Hashin, Z. and Rotem, A., 1973, A Fatigue Criterion for Fiber Reinforced Materials, $J$. of Composite Mater., Vol. 7, pp. 448-464.

11. Awerbuch, J. and Hahn, H. T., 1981, Off-Axis Fatigue of Graphite/Epoxy Composite, Fatigue of Fibrous Composite Materials, ASTM STP 723, American Society for Testing and Materials, pp. 243-273.

12. Ramakrishna, S., 1997, Characterization and Modeling of the Tensile Properties of Plain WeftKnit Fabric-Reinforced Composites, Comp. Sci. \& Tech., Vol. 57, pp. 1-22.

13. Hamada, H., Fujita, A., Yokoyama, A., \& Maekawa, Z., 1994, Unified Approach for Predicting Mechanical Behaviors of Textile Composites, Proc. ACS-meeting, Delaware(USA), pp. 377-385.

14. Huysmans, G., Gommers, B., \& Verpoest, I., 1997, A Binary Finite Element Model for the Effective Stiffness Prediction of 2D Warp Knitted fabric Composites, Proc. $4^{\text {th }}$ Int. Conf. on Deformation and Fracture of Comp., Manchester (UK), pp. 309-318.

15. Gowayed, Y. A., Hwang, J., \& Chapman, D., 1995, Thermal Conductivity of Textile Composites with Arbitrary Perform Structures, ASTM J. Comp. Tech. \& Res., Vol. 17, No. 1, pp. 56-62.

16. Gowayed, Y. A., 1997, The effect of Voids on the Elastic Properties of Textile Reinforced Composites, ASTM J. Comp. Tech. \& Res., Vol. 19, No. 3, pp. 168-173. 
17. Ramakrishna, S., 1998, Analytical and Finite Element Modeling of Elastic Behavior of PlainWeft Knitted Fabric Reinforced Composites, Key Eng. Mater., Vol. 137, pp. 71-78.

18. Huang, Z. M., 2001, Simulation of the Mechanical Properties of Fibrous Composites by the Bridging Micromechanics Model, Composites Part A, Vol. 32, No. 2, pp. 143-172.

19. Huang, Z. M. and Ramakrishna, S., Modeling Mechanical Properties of Knitted Fabric Composites-Part II: Theoretical Description, Science \& Engineering of Composite Materials, Vol. 10, No. 3, pp. 189-211.

20. Huang, Z. M. and Ramakrishna, S., Modeling Mechanical Properties of Knitted Fabric Composites-Part III: Application Results, Science \& Engineering of Composite Materials, Vol. 10, No. 3, pp. 213-239.

21. Gohl, E. P. G. and Vilensky, L. D., 1991, Knitting, Textile for Modern Living, $4^{\text {th }}$ Edition, Longman Cheshire, pp. 213-245.

22. Ramakrishna, S., Hamada, H., Kanamaru, R. and Maekawa, Z., Mechanical Properties of 2.5 Dimensional Warp Knitted Fabric Reinforced Composites, Design and Manufacture of Composites, edited by S.V. Hoa, Corcordia University, Montreal, 1994, pp. 254-263.

23. Leaf, G. A. V. \& Glaskin, A., 1955, The Geometry of A Plain Knitted Loop, J. Text. Inst., Vol. 45, T587-T605.

24. Huang, Z. M., Ramakrishna, S., Dinner, H. P., and Tay, A. A. O., 1999. Characterization of a Knitted Fabric Reinforced Elastomer Composite, J. Reinf.
Plast. \& Comp., Vol. 18, No. 2, pp. 118-137.

25. Toll, S. and Andersson, P. O., 1991, Micromechanical Characterization of Injection Molded Composites using Image Analysis, Composites, Vol. 22, pp. 298-306.

26. Ramakrishna, S., Huang, Z. M., Teoh, S. H., Tay, A. A. O., and Chew, C. L., 2000, Application of Leaf and Glaskin's Model for Estimating the 3D Elastic Properties of Knitted Fabric Reinforced Composites, J. Text. Inst., Vol. 91 Part 1, No. 1, pp. 1-19.

27. Huang, Z. M., Ramakrishna, S. and Leong, K. H., 2002, Modeling the Tensile Behavior of Milano Rib Knit Fabric Composites, J. Reinf. Plastics \& Comp. Vol. 21, No. 12, pp. 1123-1146.

28. Leong, K. H., Falzon, P. J., Bannister, M. K. and Herszberg, I., 1998, An Investigation of the Mechanical Performance of Weft-Knitted Milano Rib Glass/Epoxy Composites, Comp. Sci. \& Tech., Vol. 58, pp. 239-251.

29. Anwar, K. O. et al., 1997, The Effect of architecture on the Mechanical Properties of Knitted Composites, $1 l^{\text {th }}$ Int. Conf. on Comp. Mater, ICCM-11, Golden Coast, Australia, July 14-18, pp. V328-227.

30. ASTM D3171-76, Standard Test Method for Fiber Content of Resin-Matrix Composites by Matrix Digestion.

31. Ruan, X. P. and Chou, T. W., 1996, Experimental and Theoretical Studies of the Elastic Behavior of Knitted-Fabric Composites, Comp. Sci. \& Tech., Vol. 56, pp. 1391-1403. 